Columbia Business School
Center on Japanese Economy and Business

CENTER ON JAPANESE ECONOMY AND BUSINESS

日本经济经営研究所

Working Paper Series

July 2016, No. 353

\title{
When Are Uninformed Boards Preferable?
}

\author{
Naoto Isaka
}

COLUMBIA UNIVERSITY IN THE CITY OF NEW YORK 


\title{
When Are Uninformed Boards Preferable?*
}

\author{
Naoto Isaka ${ }^{\dagger}$ \\ July 13, 2016
}

\begin{abstract}
In this paper, I analyze the optimal choice of board of directors using the dualrole model of boards in Adams and Ferreira (2007). In my model, shareholders choose either an informed board that brings additional private information to the firm or an uninformed board that merely considers the inside information already available within the firm. The board then randomly chooses a good chief executive officer (CEO) with inside information or a bad CEO without such information, and the CEO decides whether to consult with the board when making a project decision. I show that shareholders generally choose the informed board to maximize firm value by utilizing the private information available to the board. However, the shareholders optimally select the uninformed board if the CEO is reluctant to communicate with the informed board for fear it will reject the CEO's decision. The uninformed board is also optimal when the board has a sufficiently large private benefit of monitoring the CEO, the shareholders feel burdened by any conflict between the CEO and the board, or the firm is involved in many unrelated businesses, especially when the inside information is valuable and the firm needs many outsiders to observe useful outside information. I use some of these implications and casual observation of real-world data to discuss recent trends in the board structure of Japanese firms.
\end{abstract}

${ }^{*}$ I would like to thank Harue Isaka, Masako Kurosawa, Ryoko Ogino, Kazuhiko Ohashi, Masanori Orihara, Hugh Patrick, Katsumi Tanabe, David E. Weinstein, Haoyong Zhou, and seminar participants at the Center on Japanese Economy and Business (CJEB), Columbia University, and participants at the 2015 annual meeting of the Nippon Finance Association, and the 27th Australasian Finance and Banking Conference for their helpful comments and suggestions. This research has been conducted at Sophia University and also at the CJEB while I stayed there as a visiting fellow, and was supported by a research grant from Sophia University.

${ }^{\dagger}$ Faculty of Liberal Arts, Sophia University. 7-1 Kioi-cho, Chiyoda-ku, Tokyo, Japan 102-8554; Tel: +81-3-3238-4059; E-mail: nisaka@sophia.ac.jp 


\section{Introduction}

The role of corporate boards of directors has become a central issue in finance in the wake of recent corporate scandals (e.g., Enron, WorldCom, and others). ${ }^{1}$ In the US, the Sarbanes-Oxley (SOX) Act of 2002 requires all firms listed on national exchanges to have a majority of independent board members, and similar laws have been introduced in many other countries, including Canada (C-SOX in 2002), France (the Financial Security Law of Finance in 2003), and Germany (the German Corporate Governance Code in 2002). ${ }^{2}$ The worldwide trend is now toward the requirement for listed companies to appoint independent board members.

In Japan, the revision of the Commercial Code in 2003 allowed firms to adopt a US-style board system, or so-called "committees system," which strengthened the monitoring role of boards and substantially differs from the traditional Japanese "audit and supervisory (Kansayaku)" system. ${ }^{3}$ In brief, a company has three committees consisting of board members (Committee on Nomination of Directors, Committee on Fees for Management Members, and Audit Committee), and each of these committees is required by law to have a majority of outside directors. Further, with the committees system, there is a clear separation between the board's supervisory function and company management in that the board of directors specializes in the supervisory role and delegates the management of the company to its executive officers. ${ }^{4}$ In contrast, a company using the "Kansayaku" system does not have this clear distinction between supervision and management because all board members are involved in both roles. In this system, the activities of the board are supervised by an audit and supervisory board known as the Kansayaku of which a majority of its members must be outsiders. However, the appointment of outside Kansayaku members is not mandatory, and importantly, the Kansayaku has only limited power to supervise management because its members do not carry voting rights in board meetings. ${ }^{5}$

\footnotetext{
${ }^{1}$ Adams, Hermalin, and Weisbach (2010), Hermalin and Weisbach (2003), and John and Senbet (1998) provide comprehensive surveys of theoretical and empirical studies on corporate governance and boards. Bebchuk and Weisbach (2010) also reviews the recent state of corporate governance research.

${ }^{2}$ Linck, Netter, and Yang (2008) investigates the effects of SOX on the supply and demand for directors, Chhaochharia and Grinstein (2007) examines the value effects of the announcement of the SOX, and Brick and Chidambaran (2010) conclude that the independence of board committees increased following the enactment of the SOX Act.

${ }^{3}$ The revision of the Commercial Code allowed only large firms with total capital in excess of 100 million yen to select the committees system. Subsequently, the enactment of the Japanese Companies Act in 2005 allowed all firms this option.

${ }^{4}$ The Companies Act Article 2 (xv) defines an "outside director" as the director of any stock company who is neither an executive director nor an executive officer, nor an employee, including managers, of such stock company or any of its subsidiaries, and who has neither ever served in the past as an executive director nor executive officer, nor as an employee, including a manager, of such stock company or any of its subsidiaries.

${ }^{5}$ In May 2015, another type of the board system known as the audit and supervisory committee system (or "Kansa" committee) was introduced in Japan. Firms can themselves choose to have this committee consisting of at least three directors, of which the majority must be outside directors. In general, the Kansa committee has less monitoring power than the committees system, but has greater monitoring power than the traditional Kansayaku system.
} 
In light of these developments, modern corporate governance in Japan has several distinct features. First, almost all Japanese firms are reluctant to choose the committees system. Of the companies listed on the Tokyo Stock Exchange (TSE), only 69 (56 in the First Section, 4 in the Second Section, 2 in the Mothers, and 7 on the JASDAQ) currently use the committees system as at May 2, 2016 according to the Japan Audit \& Supervisory Board Members Association. Although several well-known Japanese firms such as Sony, Nomura Holdings, and Mitsubishi UFJ Financial Group have adopted the committees system, $98.02 \%$ of TSE firms have not. Second, a large number of Japanese firms, including Kansayaku firms, have been rapidly increasing the number of outsiders on their boards in recent years, although the number of outside directors remains relatively small when compared with US companies. In evidence, the percentage of firms with any board outsider increased from $42.3 \%$ to $64.4 \%$ ( $40.8 \%$ to $63.8 \%$ for Kansayaku firms) from October 2006 to May 2016, while the percentage of firms with outsiders representing at least one-third of board members increased from $10.7 \%$ to $22.0 \%$ (8.8\% to $20.5 \%$ for Kansayaku firms) from September 2010 to May $2016 .{ }^{6}$ Third, there is great variability in the willingness to hire outside directors among Kansayaku firms. As discussed, in recent years Japanese firms have been generally hiring more outside directors, despite most not adopting the committees system. However, there are still many TSE firms with few outsiders on their boards. In fact, as at May 2016, 247 TSE-listed firms do not have any board outsiders and another 1,368 TSE-listed firms have only a single board outsider.

The questions are why Japanese firms choose not to adopt the committees system, and why many Kansayaku firms have continued to increase the number of their outside board directors while others have not. We can respond to some of these questions by investigating the reasons why firms wish or do not wish to have outside board members. Of course, the fact that many firms are apparently unwilling to implement an independent board is somewhat puzzling from the viewpoint of firm value maximization. For instance, it is widely believed that independent directors are beneficial for shareholder value, and several empirical studies (e.g., Byrd and Hickman (1992), Nguyen and Nielsen (2010), and Rosenstein and Wyatt (1990)) provide evidence consistent with this viewpoint. $^{7}$ More recently, Bhagat and Bolton (2013) conclude a positive and significant relationship between board independence and operating performance following the enactment of the SOX Act, and Knyazeva, Knyazeva, and Masulis (2013) also show that board independence exerts a positive effect on firm value and operating performance after controlling for endogeneity problems using local director pools as an instrument for board independence. ${ }^{8}$ More importantly, the appointment of outside directors can bring

\footnotetext{
${ }^{6}$ The May 2016 statistics are based on data retrieved from a corporate governance information search on May 7, 2016 of the TSE website, while the other statistics are from TSE (2013).

${ }^{7}$ Conversely, some empirical studies report that the value effects of independent directors are not significant and sometimes even negative (see Nguyen and Nielsen (2010)).

${ }^{8}$ Fahlenbrach, Low, and Stulz (2010) also examines the effects of the appointment of CEOs as outside directors, and Duchin, Matsusaka, and Ozbas (2010) show that the effectiveness of outside directors depends on the cost of acquiring information about the firm. Perry and Shivdasani (2005) considers the restructuring process of firms with a majority of outsiders. In addition, Saito (2011) empirically
} 
valuable outside information not available to insiders into the firm's decision-making processes. For example, Baranchuk and Dybvig (2006) develop a model predicting that boards perform better by including some directors who can bring information to the board, even if they have conflicts of interest with the other directors. Some also argue that outsiders generally have less information about the firm than do insiders, and thus cannot effectively monitor the CEO. In this regard, Ravina and Sapienza (2010) empirically examine the trading performance of independent directors and show that they do indeed have sufficient inside information about the firm.

To address the reasons why many firms prefer inside directors who have only private information available from within the firm (hereafter "inside information") and do not bring any additional private information from outside the firm ("outside information") to the firm, I analyze a model of the optimal choice of boards using the framework developed by Adams and Ferreira (2007), and investigate how private information held by the board and the CEO affects the shareholders' choice as to whether or not to adopt a board with superior information. Adams and Ferreira (2007) model the board's advising and monitoring roles and analyze how the board's endogenous monitoring intensity cost is determined. In their model, if the CEO discloses information about his project choice to the board, he can receive advice, but can also be monitored more intensively by the board. ${ }^{9}$ Their model predicts that it can be optimal for shareholders to increase monitoring intensity cost given that the CEO may be reluctant to share information if the board can easily overturn the CEO's decision. My model also relates to optimal corporate control as in Harris and Raviv $(2010,2008,2005)$ in which different parties within the firm (e.g., shareholders, management, and the board) privately observe different private information about the firm's decisions. For example, Harris and Raviv (2008) show that shareholders can be better off with an insider-controlled board when these insiders have valuable information relative to that of outsiders, even if there is an agency cost associated with insider control. ${ }^{10}$

My model extends the dual-role model in Adams and Ferreira (2007) in four ways. First, shareholders choose between an informed board and an uninformed board. If the CEO discloses his project choice to the board, the informed board observes not only inside information but also outside information about the project. In a real-world situation, if the board has a majority of outsiders, it can use additional information

investigates the boards of Japanese firms and finds that outside directors have favorable effects on firm value.

${ }^{9}$ Recently, many studies have examined the board's dual role. For example, Schwartz-Ziv and Weisbach (2013) analyze the minutes of board meetings in Israeli companies and find that boards are active monitors that play both a monitoring and an advising role. Elsewhere, Linck et al. (2008) show that board structure is consistent with the costs and benefits of the board's dual role. Faleye, Hoitash, and Hoitash (2011) also investigate the link between the intensity of board monitoring and the performance of directors.

${ }^{10}$ Their models are based on Crawford and Sobel (1982) and Dessein (2002). Other theoretical studies that analyze corporate governance and boards include Almazan and Suarez (2003), Baldenius (2013), Ferreira, Ferreira, and Raposo (2011), Hermalin and Weisbach (1998), Kumar and Sivaramakrishnan (2008), Inderst and Mueller (2010), Malenko (2013), Raheja (2005), Song and Thakor (2006), Wagner (2011), and Warther (1998). 
brought in by outsiders along with the information some insiders can access within the firm. In contrast, I assume the uninformed board observes only inside information and is unable to access any additional information outsiders may know. Second, the board randomly hires either a good CEO or a bad CEO because it cannot distinguish between good and bad CEOs prior to hiring. The good CEO observes inside information, but the bad CEO does not observe any private information. In Japan, for instance, inside board members tend to elect a firm's CEO from their own pool of members. If an elected CEO knows inside information about the project by chance, he can use it during the decision-making process. However, if an elected CEO is uninformed, he cannot use inside information unless he consults with the board, which may have some informed members. I assume that the CEO type becomes public soon after hiring, and the board then uses information about the type of the CEO to decide whether to turn down the CEO's decision. Cornelli, Kominek, and Ljungqvist (2013) find empirical evidence that boards can learn about the CEO's quality by gathering soft along with hard information. Third, I assume that both the CEO and the board derive some private benefit from taking control over the project. Each of them may be able to establish a good reputation by making important decisions regarding a firm's projects, which may assist them to secure advantageous positions in the future. Finally, in extended models, I analyze how the shareholders' cost associated with disagreement between the board and the CEO as well as firm diversification affect the choice of board, neither of which has been investigated theoretically in past studies.

My main findings are as follows. First, the shareholders generally choose the informed board to maximize firm value if the informed board's monitoring intensity cost is sufficiently large. That is, if the cost of monitoring intensity is large enough, the CEO is willing to communicate with the informed board to obtain advice because he knows that the informed board has little incentive to turn down his decision, and the shareholders can optimally choose the informed board to take advantage of its outside information. However, the shareholders optimally choose the uninformed board when the monitoring intensity cost of the informed board is sufficiently small. In this situation, both good and bad CEOs are reluctant to consult with the informed board, which is also the stricter monitor, given the fear of losing control over the project decision. The bad CEO who does not have inside information, however, has ample incentive to consult with the "uninformed board," even though the good CEO obtains no benefit from such consultation. Therefore, the shareholders choose the uninformed board intentionally to induce the bad CEO to reveal his project choice to the board. The uninformed board then becomes optimal, especially when the probability of hiring the bad CEO is high and the inside information is valuable. In support, several studies (e.g., Fracassi and Tate (2012), Shivdasani and Yermack (1999)) find that the CEO is willing to appoint less-independent directors or directors tied to the $\mathrm{CEO}$ when the $\mathrm{CEO}$ is involved in the selection of board members, even if such a decision reduces firm value. It is then possible that shareholders accept the hiring of insider directors because they also wish to appoint insiders to help the CEO communicate with the board.

Second, the shareholders also choose the uninformed board if the board derives a 
large private benefit of making decisions on the firm's project. In this situation, the informed board is eager to reject the CEO's decision to satisfy its own private benefit, even if it fails to obtain any private information regarding the project. Because the informed board's decision can harm firm value, it can be optimal for the shareholders to choose an uninformed board that has less incentive to overturn the CEO's decision. Third, the shareholders choose the uninformed board if the shareholders' cost associated with disagreement between the board and the CEO is sufficiently large. By choosing the uninformed board, which is generally friendlier to the CEO, the shareholders can reduce the risk of conflict between the board and the CEO. Finally, the uninformed board can also be optimal for a diversified firm with many unrelated businesses. In such a firm, a potential CEO and inside board members may have only a limited piece of inside information. If so, the firm may be better off choosing the uninformed board with many insiders to collect inside information through having directors from each business unit rather than choosing the informed board that can observe outside information, but may not produce enough inside information. This situation is likely to arise especially when the firm is involved in many businesses, the inside information is valuable, and the board size is relatively small compared with the number of outsiders the firm needs to have to obtain useful outside information.

In addition to these theoretical findings, I also provide an overview of the board structure of TSE-listed firms through casual observation. More specifically, I examine the relationship between the presence of foreign shareholders and board structure as well as the board structure by industry sector. I find that the firms with higher shares of foreign shareholders tend to have a larger number of outside directors on their boards. This finding is consistent with the implication of my model in that foreign shareholders typically have a smaller shareholders' cost associated with disagreement between the board and the CEO. In addition, I find that the number of board outsiders differs substantially by industry sector. Consistent with some of the model's implications, firms engaging in specialized businesses (e.g., financial, real estate, and pharmaceutical companies) tend to have a greater number of outside directors than those involved in many different businesses employing highly technological skills (e.g., machinery, automobile, and chemical companies).

The remainder of the paper is organized as follows. Section 2 presents the timing of the model and each player's preferences. Section 3 solves the model backwardly and analyzes the board's advising and monitoring decisions, the CEO's decision about whether to reveal project choice to the board, and the shareholders' optimal choice of board. Section 4 analyzes the two extended models with regard to shareholders' cost and firm diversification. Section 5 applies some of the model implications to recent trends in the board structure of TSE firms. Section 6 concludes the paper. 


\section{The Model}

\subsection{Timing of the Model}

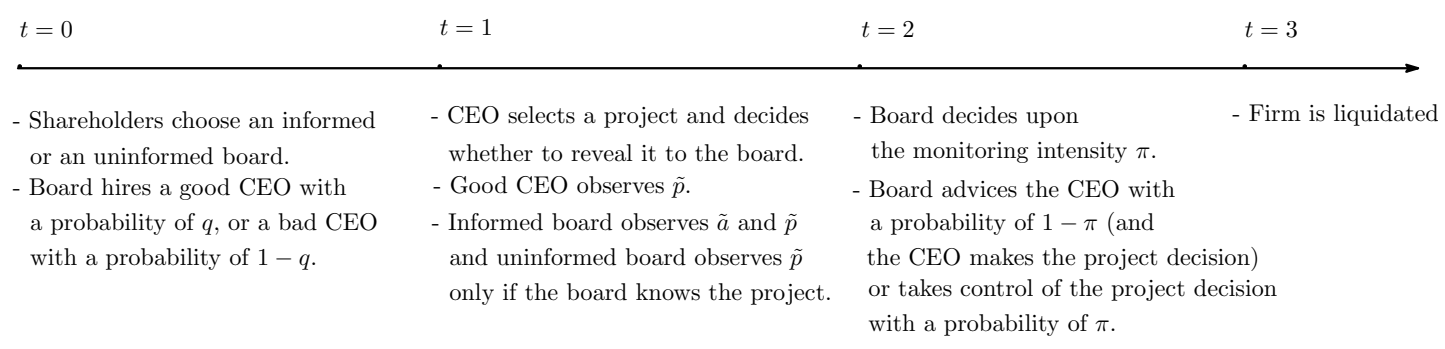

Figure 1. Timeline in the model.

Figure 1 depicts the timeline in the model. There are four periods: $t=0, t=1$, $t=2$, and $t=3$. At $t=0$, shareholders choose either an informed board $(H)$ that can potentially generate outside information (not known to the CEO) about the firm's project, or an uninformed board $(L)$ that can observe only inside information that is already available within the firm. The board type is public information known to the shareholders and the CEO. In a real world situation, we would expect a board with a majority of outsiders to acquire not only the information available inside the firm, but also some additional information not available to insiders. I assume that the uninformed board can also acquire inside information, as it is natural to think that some if not all insiders observe private information available within the firm and share it with the other board members. The selected board then hires either a good CEO $(G)$ or a bad CEO $(B)$. However, the board cannot distinguish between good and bad CEOs during the hiring process, but only knows the probability of hiring a good or bad CEO. The board can select a good CEO with a probability of $q \in[0,1]$ and a bad CEO with a probability of $1-q$. The type of the CEO is revealed to the board soon after hiring.

At $t=1$, the CEO selects a project from an infinite number of feasible projects $\theta \in \mathbb{R}$. The good CEO privately observes inside information $\tilde{p}$ about the project, which is uniformly distributed on $[0, P](P \in(0,1])$, while the bad CEO does not. Then the CEO decides whether to reveal his project choice $\theta$ to the board. If the CEO reveals $\theta$, the board can also observe private information about the project. The informed board privately observes not only $\tilde{p}$, but also outside information $\tilde{a}$ about the project, which is uniformly distributed on $[0, A](A \in(0,1])$. On the other hand, the uninformed board privately observes only $\tilde{p}$, which is the same inside information possessed by the good CEO. If the CEO does not communicate $\theta$ with the board, both the informed and uninformed boards cannot observe any private information because they cannot identify the choice of the project. The random variables $\tilde{a}$ and $\tilde{p}$ are independent, and the variances of these random variables $\sigma_{a}^{2}$ and $\sigma_{p}^{2}$ measure the importance of outside information, and that of inside information. 
At $t=2$, the board decides its monitoring intensity $\pi \in[0,1]$. With a probability of $\pi$, the board successfully monitors the CEO and has effective control over the project decision. With a probability of $1-\pi$, the board provides advice to the CEO on the project instead of opposing the CEO's decision. That is, the board sends a signal $s$ about $\tilde{a}$ and/or a signal $s^{\prime}$ about $\tilde{p}$ to the CEO, and the CEO retains the right to decide on the project. At this stage, the board knows the type of CEO and thus can set a different monitoring intensity depending on the CEO type. The firm is liquidated at $t=3$.

\subsection{Preferences}

After the CEO selects a project $\theta$, either the CEO or the board must make a decision in choosing $\boldsymbol{y}=\left(y_{a}, y_{p}\right) \in \mathbb{R}^{2}$. The loss in firm value is divided into two parts: the loss resulting from the deviation of the decision $y_{p}$ from the realization of inside information $\tilde{p}$, and the loss resulting from the deviation of the decision $y_{a}$ from the realization of outside information $\tilde{a}$. Specifically, the loss in value function is given by:

$$
\left(y_{p}-\tilde{p}\right)^{2}+\left(y_{a}-\tilde{a}\right)^{2} .
$$

Firm value is maximized by choosing a decision, $y_{a}=\tilde{a}$ and $y_{p}=\tilde{p}$. As explained in the previous subsection, the good CEO privately observes $\tilde{a}$, while the informed (uninformed) board can privately observe both $\tilde{a}$ and $\tilde{p}$ (only $\tilde{p}$ ), but only if the CEO reveals his choice of project at $t=1$.

I assume the following utility function represents the shareholders' preferences.

$$
U_{S}=-\left[\left(y_{p}-\tilde{p}\right)^{2}+\left(y_{a}-\tilde{a}\right)^{2}\right] .
$$

In this base model, the shareholders' utility is perfectly linked to firm value and is maximized when $\boldsymbol{y}=(\tilde{a}, \tilde{p})$. In Section 4.1, I analyze an extended model in which the shareholders' utility is also dependent on a cost not directly related to firm value.

The following utility function characterizes the preferences of the good and the bad CEOs.

$$
U_{i}=-\left[\left(y_{p}-\tilde{p}+g\right)^{2}+\left(y_{a}-\tilde{a}+g\right)^{2}\right]+\chi b, \quad i=G, B .
$$

where the magnitude of the management bias, $g>0$, measures the extent of an agency problem between the CEO and the board. ${ }^{11}$ Because of this parameter $g$, the CEO's utility is maximized by choosing a decision, $\boldsymbol{y}=(\tilde{a}-g, \tilde{p}-g)$ and the CEO's decisions on $y_{a}$ and $y_{p}$ will be biased. $\chi$ is an indicator function taking a value of one if the CEO retains control over the project, and zero if the board opposes the CEO's decision. The parameter $b>0$ measures the CEO's private benefit of retaining control over the project.

\footnotetext{
${ }^{11}$ We can also let both of the CEO and board have the bias, say $g_{C}>0$ and $g_{B}>0$, respectively. Then, assuming that the CEO has a larger bias than does the board (i.e., $g_{C} \geq g_{B}$ ), the effects of $g$ on our conclusions will be weakens. For example, the monitoring intensity will be smaller in Section 3.2 because $g^{2}$ will be replaced by $\left(g_{C}-g_{B}\right)^{2}$.
} 
The CEO may benefit from maintaining a decision so that he can possibly build a good reputation, which may help him obtain another position in the future. Both the good CEO and the bad CEO have the same utility function, but their decisions can differ.

Finally, the board's utility function is given by:

$$
U_{i}=-\left[\left(y_{p}-\tilde{p}\right)^{2}+\left(y_{a}-\tilde{a}\right)^{2}\right]-C\left(\pi ; I_{i}\right)+(1-\chi) d, \quad i=H, L .
$$

where the parameter $d>0$ measures the board's private benefit from taking control of the project. If the board successfully monitors the CEO, some board members may be able to establish a reputation and obtain another board position in the future. I assume, however, that the board's private benefit is smaller than or equal to the CEO's private benefit (i.e., $b \geq d$ ), which I believe is a realistic assumption. $C\left(\pi ; I_{i}\right)=\frac{\pi^{2}}{2 I_{i}}$ is the cost of monitoring the CEO with intensity $\pi$. The parameters $I_{H}, I_{L} \in(0,1]$ determine the cost of monitoring for the informed and uninformed boards, respectively. The monitoring intensity cost increases as the intensity $\pi$ increases and the parameter $I$ decreases. Adams and Ferreira (2007) also employ a quadratic monitoring cost function. In their model, the monitoring cost parameter $I$ is an endogenous variable, but $I$ is an exogenous variable in my model. I assume that outsiders have a lower monitoring cost than insiders by setting $I_{H} \geq I_{L}$. This is because outsiders are less dependent on the CEO, and thus generally less reluctant to oppose the CEO's decision than are insiders whose careers closely align with the CEO's power. For a technical reason, I assume that $2 g^{2}+d>\sigma_{p}^{2}$. With this assumption, as shown in Section 3.2, the board's monitoring intensity is always positive and there will be an interaction between the advising and monitoring at $t=2 .^{12}$

\section{Analysis of the Model}

\subsection{Advising}

This section solves the game by working backwards. At $t=2$, the project decision depends on who makes it. When the board controls the project decision, the informed board chooses $\boldsymbol{y}^{H}=\left(y_{a}^{H}, y_{p}^{H}\right)$ after observing both the observation $a$ of $\tilde{a}$ and the observation $p$ of $\tilde{p}$ if $\theta$ is revealed and nothing if $\theta$ is not revealed. Similarly, the uninformed board that observes only $p$ if it knows $\theta$ and observes no information otherwise chooses $\boldsymbol{y}^{L}=\left(y_{a}^{L}, y_{p}^{L}\right)$.

$$
\begin{gathered}
\boldsymbol{y}^{H}= \begin{cases}(a, p), & \text { if the informed board knows } \theta \\
(E(\tilde{a}), E(\tilde{p})), & \text { if the informed board does not know } \theta .\end{cases} \\
\boldsymbol{y}^{L}= \begin{cases}(E(\tilde{a}), p), & \text { if the uninformed board knows } \theta \\
(E(\tilde{a}), E(\tilde{p})), & \text { if the uninformed board does not know } \theta .\end{cases}
\end{gathered}
$$

\footnotetext{
${ }^{12}$ When the board's message is informative (i.e., $N(g, \cdot) \neq 1$ ), we have $2 g^{2} \geq \frac{3 A^{2}}{24}$. Because $\sigma_{p}^{2} \leq \frac{2 A^{2}}{24}$, we can have $2 g^{2}>\sigma_{p}^{2}$, and the assumption still holds even if $d=0$. However, if $2 g^{2} \leq \sigma_{p}^{2}$, we need some positive private benefit for the board $(d>0)$ to satisfy this assumption.
} 
Thus, the first-best outcome is achieved when the informed board is selected and it makes the project decision.

When the CEO decides on the project, the good CEO who knows the observation $p$ and the bad CEO who knows nothing, set $\boldsymbol{y}^{G}$ and $\boldsymbol{y}^{B}$, respectively. They can improve this decision by receiving advice, or a signal $s$ and $s^{\prime}$, from the board.

$$
\boldsymbol{y}^{G}= \begin{cases}(E(\tilde{a} \mid s)-g, p-g), & \text { if the good CEO receives a signal about } \tilde{a} \\ (E(\tilde{a})-g, p-g), & \text { if the good CEO receives no signal. }\end{cases}
$$

$$
\boldsymbol{y}^{B}= \begin{cases}\left(E(\tilde{a} \mid s)-g, E\left(\tilde{p} \mid s^{\prime}\right)-g\right), & \text { if the bad CEO receives a signal about } \tilde{a}, \tilde{p} \\ \left(E(\tilde{a})-g, E\left(\tilde{p} \mid s^{\prime}\right)-g\right), & \text { if the bad CEO receives a signal about } \tilde{p} \\ (E(\tilde{a})-g, E(\tilde{p})-g), & \text { if the bad CEO receives no signal. }\end{cases}
$$

where $E(\tilde{a} \mid s)\left(E\left(\tilde{p} \mid s^{\prime}\right)\right)$ is the mean of the CEO's posterior beliefs after receiving a signal $s$ about $\tilde{a}\left(s^{\prime}\right.$ about $\left.\tilde{p}\right)$ from the board.

At this stage, if the board remains uninformed about $\theta$, it cannot provide any advice to the CEO. However, if the $\mathrm{CEO}$ reveals $\theta$, the board can obtain private information $\tilde{a}$ and/or $\tilde{p}$ and send a message to the CEO about the project. A communication game between the board and the CEO then determines the quality of the board's advice. According to Harris and Raviv $(2010,2008,2005)$, when the board sends the message $s$ about $\tilde{a}$, the board will partition the support of $\tilde{a}$ into intervals $\left[a_{0}, a_{1}\right],\left[a_{1}, a_{2}\right], \ldots,\left[a_{N-1}, a_{N}\right]$, with $0=a_{0}<a_{1}<\ldots<a_{N}=A$, where the number of intervals in the Pareto-best equilibrium $^{13}$ of the game $N=N(g, A)$ is determined by management bias, $g$, and the width of the support of $\tilde{a}, A$. Specifically,

$$
\begin{aligned}
N(g, A) & =\left\langle\frac{1}{2}(\sqrt{1+2 A / g}-1)\right\rangle, \\
a_{i} & =\frac{i A}{N(g, A)}-2 g i(N(g, A)-i), \quad i=0, \ldots, N(g, A) .
\end{aligned}
$$

where $\langle x\rangle$ is the smallest integer greater than or equal to $x . N(g, A)$ is a nondecreasing (nonincreasing) function of $A(g)$ and approaches one as $A(g)$ decreases (increases). The partition of the support of $\tilde{p}$ is determined in the same way. Then the board sends a message that is randomly drawn from the partition containing $\tilde{a}$ (or $\tilde{p}$ ). If the board sends a noisy message $s \in\left[a_{i-1}, a_{i}\right]\left(s^{\prime} \in\left[p_{i-1}, p_{i}\right]\right)$, the CEO's expectation about $\tilde{a}$ $(\tilde{p})$ given $s$ becomes $E(\tilde{a} \mid s)=\frac{a_{i-1}+a_{i}}{2}\left(E\left(\tilde{p} \mid s^{\prime}\right)=\frac{p_{i-1}+p_{i}}{2}\right)$. The board's advice is more accurate when $N=N(g, \cdot)$ increases. When $N(g, \cdot)=1$, the board's message becomes completely uninformative.

The residual variances of $\tilde{a}$ and $\tilde{p}$ after the CEO receives a signal $s$ or $s^{\prime}$ from the board are denoted by $\sigma_{\epsilon}^{2}$ and $\sigma_{\eta}^{2}$. Given $a_{i}-a_{i-1}=A / N+2 g(2 i-N-1)$, the residual variance $\sigma_{\epsilon}^{2}$ becomes:

\footnotetext{
${ }^{13}$ The Pareto-best equilibrium is the most informative equilibrium with the largest feasible number of partitions.
} 


$$
\begin{aligned}
\sigma_{\epsilon}^{2} & =\frac{1}{A} \sum_{i=1}^{N} \int_{a_{i-1}}^{a_{i}}\left(\frac{a_{i-1}+a_{i}}{2}-s\right)^{2} d s \\
& =\frac{1}{12 A} \sum_{i=1}^{N}\left(a_{i}-a_{i-1}\right)^{3} \\
& =\frac{A^{2}}{12 N(g, A)^{2}}+\frac{g^{2}\left(N(g, A)^{2}-1\right)}{3} .
\end{aligned}
$$

The residual variance $\sigma_{\eta}^{2}$ is determined in the same way. The board's advice reduces the uncertainty about these random variables. That is, $\sigma_{\epsilon}^{2} \leq \sigma_{a}^{2}=A^{2} / 12$, and $\sigma_{\eta}^{2} \leq \sigma_{p}^{2}=$ $P^{2} / 12$. The equality holds when the board message does not contain any information (i.e., $N(g, \cdot)=1$ ).

\subsection{Monitoring Intensity}

Next, I analyze the board's monitoring intensity decision at $t=2$. The board's decision on the monitoring intensity depends on how the game proceeds. The monitoring intensity is a function of the parameter $I_{i},(i=H, L)$ and differs over four scenarios for each of the informed and uninformed boards. Let $i=\{H, L\}$ and $j=\{\theta, \emptyset\}$ denote the board's type and its information about $\theta$. I calculate the monitoring intensity for each of the following scenarios: (i) the good CEO reveals his project choice, $\pi_{i G}\left(j=\theta ; I_{i}\right)$, (ii) the good CEO does not reveal his project choice, $\pi_{i G}\left(j=\emptyset ; I_{i}\right)$, (iii) the bad CEO reveals his project choice, $\pi_{i B}\left(j=\theta ; I_{i}\right)$, and (iv) the bad CEO does not reveal his project choice, $\pi_{i B}\left(j=\emptyset ; I_{i}\right)$.

For the informed board, the monitoring intensity in scenario (i) solves: ${ }^{14}$

$$
\begin{aligned}
\max _{\pi \in[0,1]} & \pi E\left[-\left\{\left(y_{a}^{H}-\tilde{a}\right)^{2}+\left(y_{p}^{H}-\tilde{p}\right)^{2}\right\}+d \mid j=\theta\right] \\
& +(1-\pi) E\left[-\left\{\left(y_{a}^{G}-\tilde{a}\right)^{2}+\left(y_{p}^{G}-\tilde{p}\right)^{2}\right\} \mid j=\theta\right]-\frac{\pi^{2}}{2 I_{H}} \\
& =\max _{\pi \in[0,1]} \pi d-(1-\pi)\left(\sigma_{\epsilon}^{2}+2 g^{2}\right)-\frac{\pi^{2}}{2 I_{H}}
\end{aligned}
$$

Then the optimal level of monitoring intensity is given by:

$$
\pi_{H G}\left(j=\theta ; I_{H}\right)=I_{H}\left(\sigma_{\epsilon}^{2}+2 g^{2}+d\right) .
$$

In scenario (ii), the informed board does not know the information about the project choice and solves:

\footnotetext{
${ }^{14}$ Because $E(\tilde{a} \mid s)=\frac{a_{i+1}+a_{i}}{2}, E\left(\left(y_{a}^{H}-\tilde{a}\right)^{2} \mid j=\theta\right)=E\left[E\left(\left(\frac{a_{i+1}-a_{i}}{2}-\tilde{a}-g\right)^{2} \mid \tilde{a} \in\left[a_{i-1}, a_{i}\right]\right)\right]=\sigma_{\epsilon}^{2}+g^{2}$.
} 


$$
\begin{aligned}
\max _{\pi \in[0,1]} & \pi E\left[-\left\{\left(y_{a}^{H}-\tilde{a}\right)^{2}+\left(y_{p}^{H}-\tilde{p}\right)^{2}\right\}+d \mid j=\emptyset\right] \\
& \left.+(1-\pi) E\left[-\left\{\left(y_{a}^{G}-\tilde{a}\right)^{2}+\left(y_{p}^{G}-\tilde{p}\right)\right)^{2}\right\} \mid j=\emptyset\right]-\frac{\pi^{2}}{2 I_{H}} \\
& =\max _{\pi \in[0,1]}-\pi\left(\sigma_{a}^{2}+\sigma_{p}^{2}\right)+\pi d-(1-\pi)\left(\sigma_{a}^{2}-2 g^{2}\right)-\frac{\pi^{2}}{2 I_{H}} .
\end{aligned}
$$

The optimal level of monitoring intensity is given by:

$$
\pi_{H G}\left(j=\emptyset ; I_{H}\right)=I_{H}\left(2 g^{2}+d-\sigma_{p}^{2}\right) .
$$

In scenarios (iii) and (iv), the optimal level of monitoring intensity becomes:

$$
\begin{aligned}
& \pi_{H B}\left(j=\theta ; I_{H}\right)=I_{H}\left(\sigma_{\epsilon}^{2}+\sigma_{\eta}^{2}+2 g^{2}+d\right), \\
& \pi_{H B}\left(j=\emptyset ; I_{H}\right)=I_{H}\left(2 g^{2}+d\right) .
\end{aligned}
$$

Similarly, for the uninformed board, the monitoring intensity in each of scenarios (i), (ii), (iii), and (iv) is given by:

$$
\begin{aligned}
& \pi_{L G}\left(j=\theta ; I_{L}\right)=I_{L}\left(2 g^{2}+d\right), \\
& \pi_{L G}\left(j=\emptyset ; I_{L}\right)=I_{L}\left(2 g^{2}+d-\sigma_{p}^{2}\right), \\
& \pi_{L B}\left(j=\theta ; I_{L}\right)=I_{L}\left(\sigma_{\eta}^{2}+2 g^{2}+d\right), \\
& \pi_{L B}\left(j=\emptyset ; I_{L}\right)=I_{L}\left(2 g^{2}+d\right) .
\end{aligned}
$$

Given the assumption $2 g^{2}+d>\sigma_{p}^{2}$, all of the above monitoring intensities $\pi$ take positive values. The following results are obtained by comparing these monitoring intensities.

Proposition 1. The monitoring intensity $\pi$ has the following properties.

(a) For given $i=\{H, L\}, j=\{\theta, \emptyset\}$, and $k=\{G, B\}, \frac{\partial}{\partial I_{i}} \pi_{i k}\left(j ; I_{i}\right)>0$.

(b) For given $i=\{H, L\}, j=\{\theta, \emptyset\}$, and $k=\{G, B\}, \frac{\partial}{\partial g} \pi_{i k}\left(j ; I_{i}\right)>0$.

(c) For given $i=\{H, L\}, j=\{\theta, \emptyset\}$, and $k=\{G, B\}, \frac{\partial}{\partial d} \pi_{i k}\left(j ; I_{i}\right)>0$.

(d) For given $i=\{H, L\}$, and $k=\{G, B\}, \pi_{i k}\left(j=\theta ; I_{i}\right)>\pi_{i k}\left(j=\emptyset ; I_{i}\right)$.

(e) For given $i=\{H, L\}$, and $j=\{\theta, \emptyset\}, \pi_{i B}\left(j ; I_{i}\right)>\pi_{i G}\left(j ; I_{i}\right)$.

(f) For a given $k=\{G, B\}, \pi_{H k}\left(j=\theta ; I_{H}\right)>\pi_{L k}\left(j=\theta ; I_{L}\right)$, and $\pi_{H k}\left(j=\emptyset ; I_{H}\right) \geq$ $\pi_{L k}\left(j=\emptyset ; I_{L}\right)$. 
Result (a) states that a smaller monitoring cost leads to a larger monitoring intensity. Results (b) and (c) show that the board has an incentive to remove the management bias and to satisfy its private benefit by monitoring the CEO ${ }^{15}$ Result (d) is that, as shown in Adams and Ferreira (2007), the monitoring intensity increases when the CEO reveals the project choice to the board and the board observes private information. Moreover, result (e) states that the board is tougher on the bad CEO. That is, both the informed and uninformed boards monitor the bad CEO more intensively than they do the good CEO. Finally, the informed board is a tough monitor. As shown in result (f), the informed board has a stronger incentive to monitor than the uninformed board. If $I_{H}=I_{L}$ and $\theta$ is not revealed, however, the informed and uninformed boards have the same level of monitoring intensity.

\subsection{Decision to Reveal Information}

At $t=1$, the CEO decides whether to reveal his project choice to the board. The CEO communicates with the board if the expected utility of revealing $\theta$ is greater than or equal to that of not revealing it. In the case of the informed board, the good CEO's expected utility when he reveals $\theta, E U_{H G}\left(j=\theta ; I_{H}\right)$, and when he does not reveal it, $E U_{H G}\left(j=\emptyset ; I_{H}\right)$, are:

$$
\begin{aligned}
E U_{H G}\left(j=\theta ; I_{H}\right) & =\pi_{H G}\left(j=\theta ; I_{H}\right) E\left[-\left(\left(y_{a}^{H}-\tilde{a}+g\right)^{2}+\left(y_{p}^{H}-\tilde{p}+g\right)^{2}\right) \mid j=\theta\right] \\
& +\left(1-\pi_{H G}\left(j=\theta ; I_{H}\right)\right)\left\{E\left[-\left(\left(y_{a}^{G}-\tilde{a}+g\right)^{2}+\left(y_{p}^{G}-\tilde{p}+g\right)^{2}\right) \mid j=\theta\right]+b\right\} \\
& =-\left(\sigma_{\epsilon}^{2}-b\right)+\pi_{H G}\left(j=\theta ; I_{H}\right)\left(\sigma_{\epsilon}^{2}-2 g^{2}-b\right),
\end{aligned}
$$

and

$$
\begin{aligned}
E U_{H G}\left(j=\emptyset ; I_{H}\right) & =\pi_{H G}\left(j=\emptyset ; I_{H}\right) E\left[-\left(\left(y_{a}^{H}-\tilde{a}+g\right)^{2}+\left(y_{p}^{H}-\tilde{p}+g\right)^{2}\right) \mid j=\emptyset\right] \\
& +\left(1-\pi_{H G}\left(j=\emptyset ; I_{H}\right)\right)\left\{E\left[-\left(\left(y_{a}^{G}-\tilde{a}+g\right)^{2}+\left(y_{p}^{G}-\tilde{p}+g\right)^{2} \mid j=\emptyset\right]+b\right\}\right. \\
& =-\left(\sigma_{a}^{2}-b\right)+\pi_{H G}\left(j=\emptyset ; I_{H}\right)\left(-\sigma_{p}^{2}-2 g^{2}-b\right) .
\end{aligned}
$$

The good CEO reveals $\theta$ if $E U_{H G}\left(j=\theta ; I_{H}\right) \geq E U_{H G}\left(j=\emptyset ; I_{H}\right)$ and does not reveal it otherwise. That is, the good $\mathrm{CEO}$ reveals $\theta$ to the informed board only if:

$$
E U_{H G}\left(j=\theta ; I_{H}\right)-E U_{H G}\left(j=\emptyset ; I_{H}\right)=\left(\sigma_{a}^{2}-\sigma_{\epsilon}^{2}\right)+I_{H}\left(\sigma_{\epsilon}^{2}+\sigma_{p}^{2}\right)\left(\sigma_{\epsilon}^{2}-\sigma_{p}^{2}-b+d\right) \geq 0 .
$$

The bad CEO's expected utility of revealing $\theta, E U_{H B}\left(j=\theta ; I_{H}\right)$, and that of not revealing it, $E U_{H B}\left(j=\emptyset ; I_{H}\right)$, are:

\footnotetext{
${ }^{15}$ The increase in $g$ affects the monitoring intensity, both directly and indirectly, because it also increases $\sigma_{\epsilon}^{2}$ and $\sigma_{\eta}^{2}$.
} 


$$
\begin{aligned}
& E U_{H B}\left(j=\theta ; I_{H}\right)=-\left(\sigma_{\epsilon}^{2}+\sigma_{\eta}^{2}-b\right)+\pi_{H B}\left(j=\theta ; I_{H}\right)\left(\sigma_{\epsilon}^{2}+\sigma_{\eta}^{2}-2 g^{2}-b\right), \\
& E U_{H B}\left(j=\emptyset ; I_{H}\right)=-\left(\sigma_{a}^{2}+\sigma_{p}^{2}-b\right)+\pi_{H B}\left(j=\emptyset ; I_{H}\right)\left(-2 g^{2}-b\right) .
\end{aligned}
$$

Thus, the bad CEO reveals $\theta$ to the informed board if:

$$
\begin{aligned}
E U_{H B}\left(j=\theta ; I_{H}\right)-E U_{H B}\left(j=\emptyset ; I_{H}\right) & =\left(\sigma_{a}^{2}-\sigma_{\epsilon}^{2}\right)+\left(\sigma_{p}^{2}-\sigma_{\eta}^{2}\right) \\
& +I_{H}\left(\sigma_{\epsilon}^{2}+\sigma_{\eta}^{2}\right)\left(\sigma_{\epsilon}^{2}+\sigma_{\eta}^{2}-b+d\right) \\
& \geq 0,
\end{aligned}
$$

and does not reveal it otherwise.

When the board is uninformed, the CEO's expected utility in each scenario is given by:

$$
\begin{aligned}
& E U_{L G}\left(j=\theta ; I_{L}\right)=-\left(\sigma_{a}^{2}-b\right)+\pi_{L G}\left(j=\theta ; I_{L}\right)\left(-2 g^{2}-b\right) \\
& E U_{L G}\left(j=\emptyset ; I_{L}\right)=-\left(\sigma_{a}^{2}-b\right)+\pi_{L G}\left(j=\emptyset ; I_{L}\right)\left(-\sigma_{p}^{2}-2 g^{2}-b\right) \\
& E U_{L B}\left(j=\theta ; I_{L}\right)=-\left(\sigma_{a}^{2}+\sigma_{\eta}^{2}-b\right)+\pi_{L B}\left(j=\theta ; I_{L}\right)\left(\sigma_{\eta}^{2}-2 g^{2}-b\right) \\
& E U_{L B}\left(j=\emptyset ; I_{L}\right)=-\left(\sigma_{a}^{2}+\sigma_{p}^{2}-b\right)+\pi_{L B}\left(j=\emptyset ; I_{L}\right)\left(-2 g^{2}-b\right)
\end{aligned}
$$

In the case of the uninformed board, the good CEO always chooses not to communicate with the board because $E U_{L G}\left(j=\theta ; I_{L}\right)-E U_{L G}\left(j=\emptyset ; I_{L}\right)<0$ always holds. On the other hand, the bad CEO communicates with the board if $E U_{L B}\left(j=\theta ; I_{L}\right)-E U_{L B}(j=$ $\left.\emptyset ; I_{L}\right)=\left(\sigma_{p}^{2}-\sigma_{\eta}^{2}\right)+I_{L} \sigma_{\eta}^{2}\left(\sigma_{\eta}^{2}-b+d\right) \geq 0$ and does not communicate otherwise.

The equilibrium of the game at $t=1$ depends on the monitoring cost parameter $I_{i},(i=H, L)$. I define the cutoff parameters $I^{*}, I^{* *}$, and $I^{* * *}$ as follows:

$$
\begin{aligned}
I^{*} & = \begin{cases}\frac{\sigma_{a}^{2}-\sigma_{\epsilon}^{2}}{\left(\sigma_{\epsilon}^{2}+\sigma_{p}^{2}\right)\left(\sigma_{p}^{2}+b-\sigma_{\epsilon}^{2}-d\right)} & \text { if } \sigma_{p}^{2}+b-\sigma_{\epsilon}^{2}-d>0 \\
1, & \text { if } \sigma_{p}^{2}+b-\sigma_{\epsilon}^{2}-d \leq 0,\end{cases} \\
I^{* *} & = \begin{cases}\frac{\left(\sigma_{a}^{2}-\sigma_{\epsilon}^{2}\right)+\left(\sigma_{p}^{2}-\sigma_{\eta}^{2}\right)}{\left(\sigma_{\epsilon}^{2}+\sigma_{\eta}^{2}\right)\left(b-\sigma_{\epsilon}^{2}-\sigma_{\eta}^{2}-d\right)} & \text { if } b-\sigma_{\epsilon}^{2}-\sigma_{\eta}^{2}-d>0 \\
1, & \text { if } b-\sigma_{\epsilon}^{2}-\sigma_{\eta}^{2}-d \leq 0,\end{cases} \\
I^{* * *} & = \begin{cases}\frac{\sigma_{p}^{2}-\sigma_{\eta}^{2}}{\sigma_{\eta}^{2}\left(b-\sigma_{\eta}^{2}-d\right)} & \text { if } b-\sigma_{\eta}^{2}-d>0 \\
1, & \text { if } b-\sigma_{\eta}^{2}-d \leq 0 .\end{cases}
\end{aligned}
$$

Proposition 2. In the case of the informed board, the equilibrium is one of the following states (E1), (E2), or (E3): 
(E1) If $I_{H} \leq I^{*}$, both the good CEO and the bad CEO reveal $\theta$ to the informed board.

(E2) If $I^{*}<I_{H} \leq I^{* *}$, the good CEO does not reveal $\theta$ and the bad CEO reveals $\theta$ to the informed board.

(E3) If $I^{* *}<I_{H}$, both the good CEO and the bad CEO do not reveal $\theta$ to the informed board.

The proof is in the Appendix. The above results indicate that when the monitoring intensity cost is sufficiently large, both the good CEO and the bad CEO are willing to communicate the project choice with the informed board and obtain advice in return. This is because, in this case, the CEO knows that the board has little incentive to turn down the CEO's decision. However, when the cost of monitoring intensity is not large enough, the good CEO becomes cautious about sharing information with the board, even when the bad CEO shares it. That is, the good CEO places greater value on retaining control of the project than on obtaining advice from the board because he has his own private information. The bad CEO, however, has a stronger incentive to receive advice from the board than does the good CEO because he does not have any private information. When the board can easily reverse the CEO's decision because of a small monitoring intensity cost, both the good and bad CEOs avoid communicating with the informed board.

Proposition 3. In the case of the uninformed board, the good CEO never reveals $\theta$ to the board. The equilibrium is one of states (E4) or (E5):

(E4) If $I_{L} \leq I^{* * *}$, the good CEO does not reveal $\theta$ to the uninformed board and the bad CEO reveals $\theta$.

(E5) If $I^{* * *}<I_{L}$, both the good CEO and the bad CEO do not reveal $\theta$ to the uninformed board.

Because the uninformed board can generate only inside information the good CEO already has, the good CEO has no informational advantage from communicating with the uninformed board. However, the bad CEO who does not observe any private information is willing to communicate with the uninformed board when the cost of monitoring intensity is sufficiently large so that the board has little incentive to turn down the CEO's decision. When the monitoring cost is smaller than the cutoff level, even the bad CEO avoids communicating with the board.

Figure 2 shows the effects of the changes in $b, g$, and $d$ on $I^{*}, I^{* *}$, and $I^{* * *}$, respectively. In the left-side panels, the straight line and the dotted line represent $I^{*}$ and $I^{* *}$, respectively, and in the right-side panels, the straight line represents $I^{* * *}$. The parameter values used in these figures are $d=0.1, b=5.0, g=0.05$, and $\sigma_{a}^{2}$ and $\sigma_{p}^{2}$ are set at 

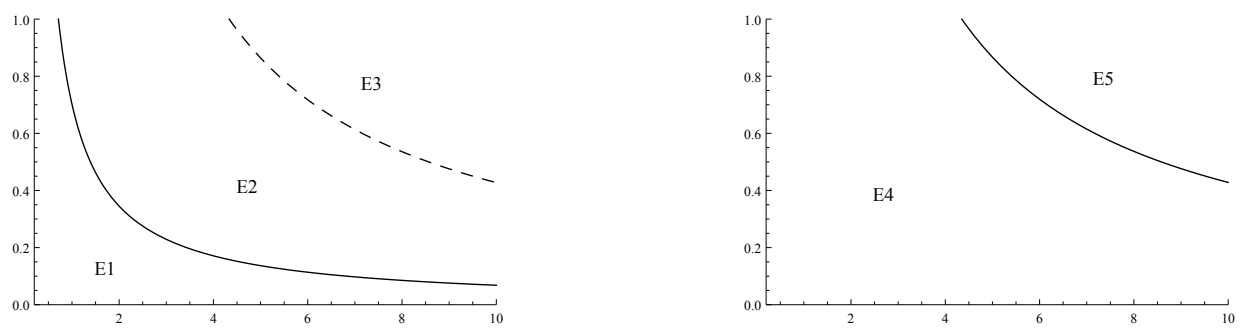

Fig. 2.1. CEO's private benefit $b$.
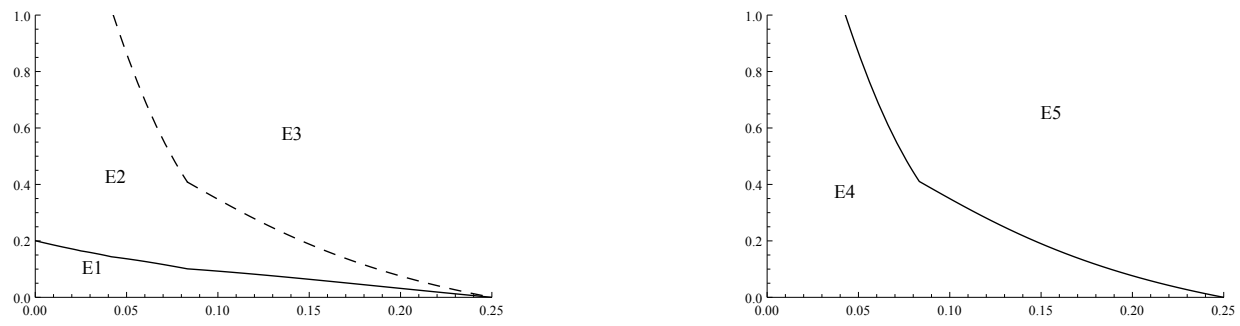

Fig. 2.2. Management bias $g$.
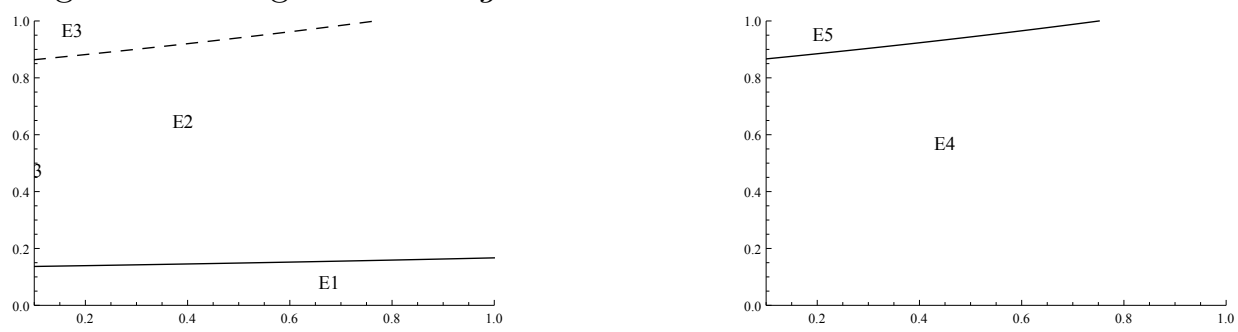

Fig. 2.3. Board's private benefit $d$.

Figure 2. Comparative statics of cutoff parameters I. Figures 2.1, 2.2, and 2.3 show the effects of the changes in $b, g$, and $d$ on $I^{*}, I^{* *}$, and $I^{* * *}$, respectively. In the left-side panels, the straight line represents $I^{*}$ and the dotted line represents $I^{* *}$. In the right-side panels, the straight line represents $I^{* * *}$. The parameter values are set at $d=0.1, b=5.0, g=0.05$, and $\sigma_{a}^{2}=\sigma_{p}^{2}=1 / 12(A=P=1.0)$, and the cutoff parameters are plotted for $0.2 \leq b \leq 10$, $0 \leq g \leq 0.25$, and $0.1 \leq d \leq 1.0$.

$1 / 12(A=P=1.0)$. States (E3), (E2), and (E1) occur when $I_{H}$ is above $I^{* *}$, between $I^{*}$ and $I^{* *}$, and below or equal to $I^{*}$, while states (E5) and (E4) occur when $I_{L}$ is above $I^{* *}$ and below or equal to $I^{*}$, respectively. In each figure, the parameter restrictions are satisfied.

As shown in Fig. 2.1, if $N(g, \cdot)>1$, each of the cutoff parameters is a decreasing function of $b$ with a decreasing slope. Consequently, the CEO is unwilling to communicate with the board when holding a larger private benefit from retaining control over the project. In particular, the good CEO is very sensitive to the change in $b$ and avoids communicating with the board, even with a small $b$. As a result, the likelihood of states (E1), (E2), and (E4) decreases, while that of states (E3) and (E5) increases with $b$. In addition, Fig. 2.2 shows that the cutoff parameters decrease as the management bias $g$ 


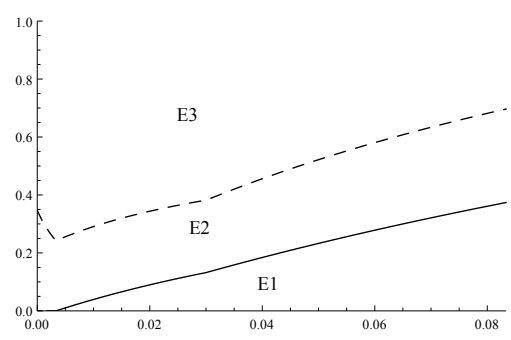

Fig. 3.1. Outside information $\sigma_{a}^{2}$.

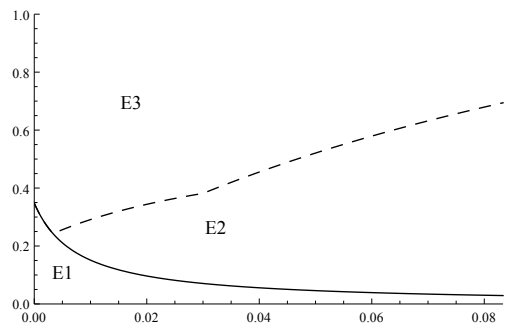

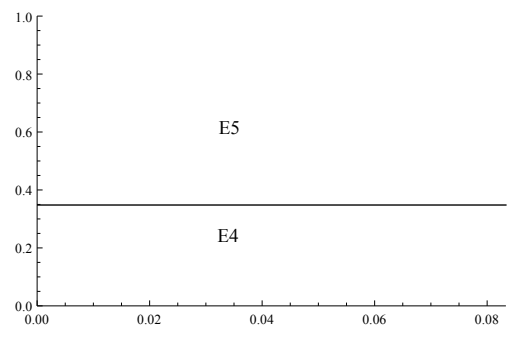

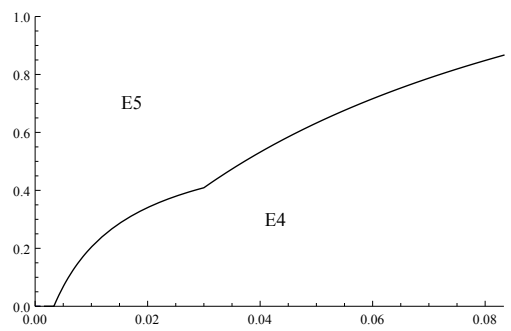

Fig. 3.2. Inside information $\sigma_{p}^{2}$.

Figure 3. Comparative statics of cutoff parameters II. Figures 3.1 and 3.2 show the effects of the changes in $\sigma_{a}^{2}$ and $\sigma_{p}^{2}$ on $I^{*}, I^{* *}$, and $I^{* * *}$, respectively. In the left-side panels, the straight line represents $I^{*}$ and the dotted line represents $I^{* *}$. In the right-side panels, the straight line represents $I^{* * *}$. The parameter values are set at $d=0.1, b=5.0$, and $g=0.05$. In Fig. 3.1, $\sigma_{p}^{2}=1 / 48(P=0.5)$ and $0 \leq \sigma_{a}^{2} \leq 1 / 12(0 \leq A \leq 1.0)$, and in Fig. 3.2, $\sigma_{a}^{2}=1 / 48$ $(A=0.5)$ and $0 \leq \sigma_{p}^{2} \leq 1 / 12(0 \leq P \leq 1.0)$.

increases. When $g$ takes a smaller value, the CEO has a stronger incentive to consult with the board because the board's message becomes more accurate. In particular, the bad CEO, who does not have any private information, is eager to consult with the board in this situation. Conversely, the CEO has less incentive to communicate with the board when $g$ becomes larger. This is because when the agency problem is severe, the board's message becomes less precise. Therefore, the likelihood of states (E2) and (E4) is high when $g$ takes a small value, while that of states (E3) and (E5) increases with $g$. All the cutoff parameters becomes zero when $N(g, \cdot)=1$, as the board's signal does not convey any information (i.e., $\sigma_{a}^{2}=\sigma_{\epsilon}^{2}$ and $\sigma_{p}^{2}=\sigma_{\eta}^{2}$ ). As shown in Fig. 2.3, if $N(g, \cdot)>1$, the effect of an increase in $d$ on each cutoff parameter is positive. The CEO, especially the bad CEO, has greater incentive to reveal $\theta$ to the board as the likelihood of states (E2) and (E4) increases with $d$. When the board has a larger private benefit, the decision maker is more likely to be the board itself. Thus, the CEO chooses to reveal $\theta$ to allow the board to observe private information.

Figure 3 depicts the effects of the changes in $\sigma_{a}^{2}$ and $\sigma_{p}^{2}$ on $I^{*}, I^{* *}$, and $I^{* * *}$, respectively. The parameter values are set at $d=0.1, b=5.0$, and $g=0.05$. In Fig. $3.1, \sigma_{p}^{2}=1 / 48$ and $0 \leq \sigma_{a}^{2} \leq 1 / 12$, and in Fig. 3.2, $\sigma_{a}^{2}=1 / 48$ and $0 \leq \sigma_{p}^{2} \leq 1 / 12$, respectively. The effects of the changes in $\sigma_{a}^{2}$ and $\sigma_{p}^{2}$ on the cutoff parameters are totally different. As shown in Fig. 3.1, both $I^{*}$ and $I^{* *}$ generally increase as $\sigma_{a}^{2}$ becomes larger, 
although these functions exhibit some discontinuities when the board changes its advising strategy. In the case of the informed board, both the good and the bad CEO have a stronger incentive to communicate with the board when outside information becomes more valuable. Thus, state (E1) is more likely to occur, whereas the likelihood of state (E3) becomes less when $\sigma_{a}^{2}$ increases. As is obvious from the equation, $\sigma_{a}^{2}$ has no impact on $I^{* * *}$. In contrast, Fig. 3.2 shows that the change in $\sigma_{p}^{2}$ exerts an asymmetric effect on the behaviors of the good and bad CEOs. When the firm's inside information becomes valuable, the good $\mathrm{CEO}$ already knows it has less incentive to communicate with the informed board, but the bad CEO, who does not know this, has a stronger incentive to seek advice from either the informed or uninformed board. As a result, in the case of the informed board, state (E2) is more likely to occur while the likelihood of states (E1) and (E3) decreases as $\sigma_{a}^{2}$ becomes large. In the case of the uninformed board, the likelihood of state (E4) becomes higher, while that of state (E5) becomes lower as outside information becomes more important.

\subsection{Optimal Board}

Lastly, I consider the optimal choice of board structure. At $t=0$, the shareholders select either the informed board or the uninformed board by comparing the expected utility attached to each choice. If the informed board is selected, one of states $(E 1)$, $(E 2)$, or $(E 3)$ occurs depending upon the value of $I_{H}$, and the shareholders receive the corresponding expected utility, $E\left(U_{S}(k)\right), k=\{E 1, E 2, E 3\}$. For instance, the shareholders' utility when state (E1) occurs is given by:

$$
\begin{aligned}
E\left(U_{S}(E 1)\right) & =q\left[\pi_{H G}(\theta) E\left(-\left(\left(y_{a}^{H}-\tilde{a}\right)^{2}+\left(y_{p}^{H}-\tilde{p}\right)^{2}\right) \mid j=\theta\right)\right. \\
& \left.+\left(1-\pi_{H G}(\theta)\right) E\left(-\left(\left(y_{a}^{G}-\tilde{a}\right)^{2}+\left(y_{p}^{G}-\tilde{p}\right)^{2}\right) \mid j=\theta\right)\right] \\
& +(1-q)\left[\pi_{H B}(\theta) E\left(-\left(\left(y_{a}^{H}-\tilde{a}\right)^{2}+\left(y_{p}^{H}-\tilde{p}\right)^{2}\right) \mid j=\theta\right)\right. \\
& \left.+\left(1-\pi_{H B}(\theta)\right) E\left(-\left(\left(y_{a}^{B}-\tilde{a}\right)^{2}+\left(y_{p}^{B}-\tilde{p}\right)^{2}\right) \mid j=\theta\right)\right] .
\end{aligned}
$$

Similarly, when the uninformed board is selected, either state $(E 4)$ or $(E 5)$ occurs depending on the value of $I_{L}$, and the shareholders receive the corresponding expected utility, $E\left(U_{S}(l)\right), l=\{E 4, E 5\}$. As there are three possible states if the informed board is selected and there are two possible states if the uninformed board is selected, it is sufficient to consider the six possible combinations of the equilibrium states: $(E 1, E 4)$, $(E 2, E 4),(E 3, E 4),(E 1, E 5),(E 2, E 5)$, and $(E 3, E 5)$. The shareholders choose the informed board if $E\left(U_{S}(k)\right)-E\left(U_{S}(l)\right) \geq 0, k=\{E 1, E 2, E 3\}, l=\{E 4, E 5\}$ and the uninformed board if $E\left(U_{S}(k)\right)-E\left(U_{S}(l)\right)<0$.

Proposition 4. Shareholders' optimal choice of a board is such that:

(a) In states $(E 1, E 4)$ and $(E 1, E 5)$, the shareholders always choose the informed board. 
(b) In states $(E 2, E 4),(E 2, E 5)$, and $(E 3, E 5)$, there are $d_{(E 2, E 4)}^{*}, d_{(E 2, E 5)}^{*}, d_{(E 3, E 5)}^{*} \geq$ 0 such that the informed board is chosen if $d \leq d_{(\cdot, \cdot)}^{*}$, and the uninformed board is chosen if $d>d_{(\cdot, \cdot)}^{*}$.

(c) In state $(E 3, E 4)$, the uninformed board is chosen if $q\left(I_{H}-I_{L}\right)\left(2 g^{2}-\sigma_{p}^{2}\right)\left(2 g^{2}-\right.$ $\left.\sigma_{p}^{2}+d\right)+(1-q)\left[\left(\sigma_{\eta}^{2}-\sigma_{p}^{2}\right)+I_{H} 2 g^{2}\left(2 g^{2}+d\right)-I_{L}\left(\sigma_{\eta}^{2}+d+2 g^{2}\right)\left(\sigma_{\eta}^{2}+2 g^{2}\right)\right]<0$, and the informed board is chosen otherwise. In particular, if $I_{H}=I_{L}$, the shareholders always choose the uninformed board.

The above proposition confirms that the optimal board is generally the informed board except for state $(E 3, E 4)$. Result (a) shows that in states $(E 1, E 4)$ and $(E 1, E 5)$, the shareholders can achieve the first-best outcome by choosing the informed board if the board successfully rejects the CEO's decision. In this state, both the good and the bad CEOs are willing to reveal $\theta$ to the informed board, as the board's monitoring cost is sufficiently high. So the informed board can be a perfect decision maker that can set $\boldsymbol{y}^{H}=(a, p)$ and eliminate the agency cost $g$ by monitoring the CEO. Even if the informed board fails to monitor the CEO, it can assist the CEO in making a better decision by sending a message about $\tilde{a}$ and $\tilde{p}$. As shown in result (b), it is also optimal for the shareholders to choose the informed board in states $(E 2, E 4),(E 2, E 5)$, and $(E 3, E 5)$ if the board's private benefit $d$ is relatively small. However, if the board has a sufficiently large $d$, the shareholders optimally choose the uninformed board. In this situation, the informed board is a better choice if the bad CEO is hired. However, if the good CEO is hired, and does not reveal $\theta$, then the informed board may make a poorer decision than does the good CEO. This is because the informed board, which wishes to satisfy its private benefit, overturn the CEO's decision excessively, even if it fails to observe any private information, and can therefore harm firm value. Therefore, the uninformed board, which has less incentive to monitor the CEO, can represent a better choice.

More interestingly, result (c) implies that the shareholders always choose the uninformed board in state $(E 3, E 4)$ if the informed and uninformed boards face the same monitoring intensity cost (i.e., $I_{H}=I_{L}$ ). Actually, in this case, the good CEO is indifferent to the choice of board, and only the bad CEO changes his behavior depending on the board type. Even if the monitoring intensity cost differs for the two boards, the left-hand side of the equation in result (c) generally becomes negative unless we assume extreme parameter values, and thus it is optimal for the shareholders to choose the uninformed board. In this state, choosing the uninformed board has two advantages. The first is, as in the other states, that the shareholders can avoid the informed board's incorrect decision when $d$ is large. The second advantage, which has a more pronounced effect than the first, is that the shareholders can encourage the bad CEO to reveal $\theta$ to the board, which results in a better corporate decision. This is because, in state $(E 3, E 4)$, both the good and the bad CEOs avoid communicating with the informed board for fear of losing control over the decision. However, the bad CEO still has an incentive to share information with the uninformed board. Therefore, the shareholders rationally choose 


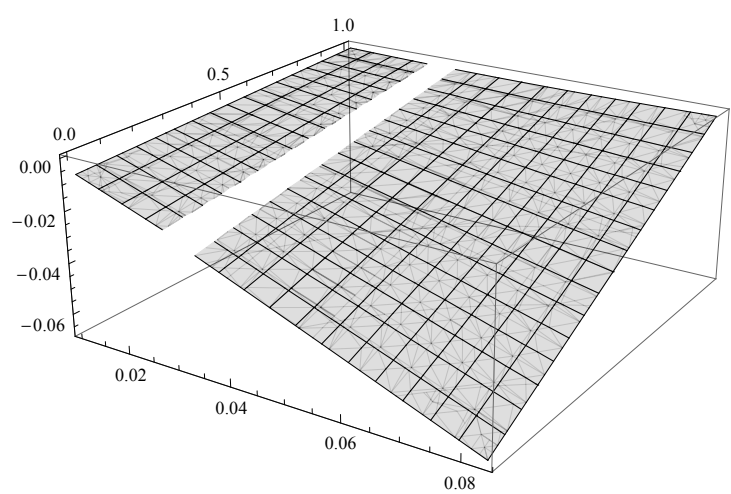

Figure 4. Comparative statics in $(E 3, E 4)$. The figure shows the effects of the change in $q$ and $\sigma_{p}^{2}$ on the left-hand side of the equation in (c) of Proposition 4. The parameters are set at $d=0.1, I_{H}=0.9, I_{L}=0.2, g=0.05,0 \leq q \leq 1.0$, and $0.01 \leq \sigma_{p}^{2} \leq 1 / 12$.

the uninformed board in order to induce the bad CEO to reveal his project choice.

Figure 4 illustrates how the probability of hiring the bad CEO, $1-q$, and the importance of inside information, $\sigma_{p}^{2}$, affect the left-hand side of the equation in result (c). The parameters are set at $d=0.1, I_{H}=0.9, I_{L}=0.2$, and $g=0.05 .{ }^{16}$ As shown, the value of this equation becomes smaller as $1-q$ approaches one and $\sigma_{p}^{2}$ approaches $1 / 12$ (i.e., $P \rightarrow 1.0$ ). That is, the shareholders have more incentive to appoint the uninformed board when the probability of hiring the bad CEO is higher and the firm's inside information held by the uninformed board becomes more valuable. This is because, in this situation, the shareholders can greatly improve firm value by inducing the bad CEO to communicate with the board.

\section{Extensions}

The basic model reveals that the shareholders select the informed board unless the board has a strong incentive to monitor the CEO. A question is whether it is always optimal for the shareholders to choose the informed board when the board has a large monitoring intensity cost. In this section, I extend the basic model and consider two situations in which the shareholders may choose the uninformed board, even if the informed board's monitoring intensity cost is relatively large. More specifically, these extended models consider how the shareholders' cost associated with a disagreement between the board and the CEO and the magnitude of firm diversification affect the shareholders' choice of board.

\footnotetext{
${ }^{16}$ The equation is not continuous because the board changes its advising strategy as $\sigma_{p}^{2}$ changes.
} 


\subsection{Shareholders' Cost}

In this subsection, I analyze an extended model in which the shareholders incur some physical or psychological costs not directly related to firm value when the board rejects the CEO's decision. Specifically, I add a parameter $c>0$ that measures the cost of the shareholders to their utility function as:

$$
U_{S}=-\left[\left(y_{p}-\tilde{p}\right)^{2}+\left(y_{a}-\tilde{a}\right)^{2}\right]-(1-\chi) c .
$$

As $\chi$ is an indicator function taking a value of one if the CEO retains control over the project and zero otherwise, the shareholders incur a positive cost $c$ only when the board stands against the CEO's decision.

This change does not alter the board's decisions on advising and monitoring intensity nor the CEO's decision to reveal $\theta$. Thus, the results in Propositions 1, 2 , and 3 do not change. In addition, the uninformed board is preferable, even with a small $c$ in state $(E 3, E 4)$, and also in states $(E 2, E 4),(E 2, E 5)$, and $(E 3, E 5)$ if the board's private benefit $d$ is sufficiently large, as shown in the results of (b) and (c) of Proposition 4 . The following proposition, however, shows that the uninformed board can be optimal even in states $(E 1, E 4)$ and $(E 1, E 5)$ if the shareholders' cost $c$ is sufficiently large.

Proposition 5. Assume that the shareholders incur cost $c>0$ when the board conflicts with the CEO. Then, in states $(E 1, E 4)$ and $(E 1, E 5)$, there are $c_{(E 1, E 4)}^{*}, c_{(E 1, E 5)}^{*} \geq 0$ such that the informed board is chosen if $c \leq c_{(,,)}^{*}$, and the uninformed board is chosen if $c>c_{(\cdot, \cdot)}^{*}$.

This proposition confirms that the optimal board is generally the informed board unless the shareholders incur a large cost in rejecting the CEO's decision. It is usually best for the shareholders to elect outsiders who can bring outside information to the firm during the decision-making process rather than selecting uninformed insiders. However, the shareholders choose the uninformed board if they have a large $c$ and do not wish to see conflict between the CEO and the board. The shareholders know that the informed board is more likely to reject the CEO's decision and thus prefer the uninformed board if $c$ is large enough to offset the benefit of using outside information.

\subsection{Firm Diversification}

Next, I examine the effects of firm diversification on the board choice. Throughout this subsection, I assume that an insider in a diversified firm with a larger number of business units has a smaller piece of inside information relative to the firm's entire business. Let $N \in \mathbb{N}$ be the magnitude of firm diversification possibly measured by the number of business units in the firm. The larger the value of $N$, the more diversified the firm. Additionally, let $M, L \in \mathbb{N}$ such that $M \geq N, L$ denotes the board size, and the necessary number of outside board members the firm needs to acquire outside information $\tilde{a}$, and let $r \in[0,1]$ determine the fraction of inside information $\tilde{p}$ the informed board can observe. 
I then assume that the probability of hiring a good CEO is a nonincreasing function of $N$, which satisfies $q(1)=1$ and $\lim _{N \rightarrow \infty} q(N)=0$. If a firm is involved in many unrelated businesses, each employee can observe only a limited piece of inside information, and it then becomes difficult for the board to hire a good CEO with sufficient inside information about the project. Because of $M \geq N$, the board size is large enough to collect all the pieces of inside information by appointing a director from each business unit if the firm does not have any outside directors. Thus, if the uninformed board is chosen, the board can perfectly observe $\tilde{p}$. On the other hand, if the informed board is chosen, the amount of inside information observed by the board is a nondecreasing function of $\alpha \equiv \frac{M-L}{N}$, which satisfies $r(\alpha)=1$ if $\alpha \geq 1$, and $\lim _{\alpha \rightarrow 0} r(\alpha)=0$. Intuitively, $M-L$ represents the number of insiders on the board, and if $M-L$ is large enough to cover all the business units $N$, the informed board can observe not only $\tilde{a}$ but also $\tilde{p}$. However, if $\alpha<1$, the informed board can observe $\tilde{a}$ and only a fraction of $\tilde{p}$, and the amount of $\tilde{p}$ the informed board can observe decreases as $\alpha$ becomes smaller. This situation arises when a diversified firm with a large value of $N$ has a relatively small board or when it needs to appoint many outsiders on the board to obtain useful outside information.

More specifically, for the informed board, I divide the inside information $\tilde{p}$ into $r(\alpha) \tilde{p_{1}}$ and $(1-r(\alpha)) \tilde{p_{2}}$, where $\tilde{p_{1}}$ and $\tilde{p_{2}}$ are independent (also independent of $\tilde{a}$ ) and follow the same uniform distribution as $\tilde{p}$. The management bias associated with $r \tilde{p_{1}}$ and $(1-r) \tilde{p_{2}}$ is assumed to be $r g$ and $(1-r) g$, respectively. At the advising stage, the informed board observes not only $\tilde{a}$ but also $r \tilde{p_{1}}$, but cannot observe $(1-r) \tilde{p_{2}}$, even if $\theta$ is revealed. As a result, its decision becomes:

$$
\boldsymbol{y}^{H}= \begin{cases}\left(a, r p_{1}+(1-r) E\left(\tilde{p_{2}}\right)\right), & \text { if the informed board knows } \theta \\ (E(\tilde{a}), E(\tilde{p})), & \text { if the informed board does not know } \theta .\end{cases}
$$

The decisions of the uninformed board and the good CEO are the same as in our basic model. The decision of the bad CEO, however, changes to $\boldsymbol{y}^{B}=\left(E(\tilde{a} \mid s)-g, r E\left(\tilde{p_{1}} \mid s^{\prime}\right)+\right.$ $\left.(1-r) E\left(\tilde{p_{2}}\right)-g\right)$ only when he receives advice from the informed board, but his decision does not change in the remaining situations.

With these changes, the optimal level of monitoring intensity changes only for $\pi_{H G}(j=$ $\theta)$ and $\pi_{H B}(j=\theta)$ as follows:

$$
\begin{aligned}
& \pi_{H G}\left(j=\theta ; I_{H}\right)=I_{H}\left(\sigma_{\epsilon}^{2}+2 g^{2}+d-(1-r)^{2} \sigma_{p}^{2}\right), \\
& \pi_{H B}\left(j=\theta ; I_{H}\right)=I_{H}\left(\sigma_{\epsilon}^{2}+r^{2} \sigma_{\eta}^{2}+2 g^{2}+d\right) .
\end{aligned}
$$

When $r=1$, the monitoring intensity is the same as in the basic model. However, as $r \downarrow 0$, or $\alpha \downarrow 0$, the monitoring intensity lessens because the informed board can observe only a fraction of $\tilde{p}$ and has less of an information advantage.

These changes also affect the CEO's decision about whether to communicate with the informed board. Propositions 2 and 3 continue to hold, but the cutoff parameters $I^{*}$ and $I^{* *}$ deviate from those of the basic model as $r \downarrow 0$, or $\alpha \downarrow 0$, and should be modified as: 


$$
\begin{aligned}
I^{*} & = \begin{cases}\frac{\sigma_{a}^{2}-\sigma_{\epsilon}^{2}}{\left(\sigma_{\epsilon}^{2}+r^{2} \sigma_{p}^{2}\right)\left(\left(2-r^{2}\right) \sigma_{p}^{2}+b-\sigma_{\epsilon}^{2}-d\right)} & \text { if }\left(2-r^{2}\right) \sigma_{p}^{2}+b-\sigma_{\epsilon}^{2}-d>0 \\
1, & \text { if }\left(2-r^{2}\right) \sigma_{p}^{2}+b-\sigma_{\epsilon}^{2}-d \leq 0,\end{cases} \\
I^{* *} & = \begin{cases}\frac{\left(\sigma_{a}^{2}-\sigma_{\epsilon}^{2}\right)+r^{2}\left(\sigma_{p}^{2}-\sigma_{\eta}^{2}\right)}{\left(\sigma_{\epsilon}^{2}+r^{2} \sigma_{\eta}^{2}\right)\left(b-\sigma_{\epsilon}^{2}-r^{2} \sigma_{\eta}^{2}-d\right)} & \text { if } b-\sigma_{\epsilon}^{2}-r^{2} \sigma_{\eta}^{2}-d>0 \\
1, & \text { if } b-\sigma_{\epsilon}^{2}-r^{2} \sigma_{\eta}^{2}-d \leq 0,\end{cases}
\end{aligned}
$$

In the case of the informed board, as $r$ approaches one, the likelihood of (E3) increases, and the bad CEO has more incentive to communicate with the board to obtain inside information.

The following proposition states that even if the informed board has little incentive to act against the CEO's decision, the shareholders of a diversified firm may prefer to choose the uninformed board instead of the informed board.

Proposition 6. In this extended model, if $r(\alpha)=1$, the shareholders always choose the informed board in state $(E 1, E 4)$ and also in state $(E 2, E 4)$ if $d \leq d_{(E 2, E 4)}^{*}$. However, if $r(\alpha)<1$, the shareholders may choose the uninformed board even with a small $d$. In particular, if $\alpha \downarrow 0$ and $N \uparrow \infty$, the uninformed board is chosen if $\left(\sigma_{a}^{2}-\sigma_{\epsilon}^{2}\right)-\left(\sigma_{p}^{2}-\right.$ $\left.\sigma_{\eta}^{2}\right)+I_{H} \sigma_{\epsilon}^{2}\left(\sigma_{\epsilon}^{2}+2 g^{2}\right)-I_{L} \sigma_{\eta}^{2}\left(\sigma_{\eta}^{2}+2 g^{2}\right)+\left(I_{H}-I_{L}\right)\left(2 g^{2}+d\right)\left(2 g^{2}+\sigma_{\epsilon}^{2}+\sigma_{\eta}^{2}\right)<0$ and the informed board is chosen otherwise.

In Proposition 6, the condition for selecting the uninformed board if $r(\alpha)=0$ and $q(N)=0$ (i.e., $\alpha \downarrow 0$ and $N \uparrow \infty$ ) can be simplified further by assuming that both types of board have the same monitoring intensity cost (i.e., $I_{H}=I_{L}$ ) and that both of the residual variances are negligible (i.e., $\sigma_{\epsilon}^{2}=\sigma_{\eta}^{2} \approx 0$ ). Then the uninformed board is preferred when, for the bad CEO, the benefit of receiving advice on inside information is larger than that of receiving advice on outside information (i.e., $\sigma_{p}^{2}-\sigma_{\eta}^{2}>\sigma_{a}^{2}-\sigma_{\epsilon}^{2}$ ). Firm diversification then affects board choice via two channels. The first is that as the magnitude of firm diversification rises, any potential CEO has only a small piece of inside information. Thus, the board can play an important role in collecting enough inside information by appointing some insiders from each business unit to the board. The second channel is that if the diversified firm has too many outside directors relative to board size, it may fail to collect enough inside information. Therefore, if inside information is more valuable than outside information, the shareholders may prefer to choose the uninformed board that cannot produce any outside information, but can collect inside information and use it during the firm's decision-making process.

In states $(E 1, E 5)$ and $(E 2, E 5)$, the shareholders always choose the informed board if $r(\alpha)=1$ and $d \leq d_{(E 2, E 5)}^{*}$, and still choose the informed board even if $q(N)=r(\alpha)=0$. In states $(E 3, E 4)$ and $(E 3, E 5), q(N)$ affects board choice but $r(\alpha)$ does not. In state $(E 3, E 4)$, as mentioned in the previous section, the shareholders have a greater incentive to choose the uninformed board as $1-q(N)$ becomes larger. Therefore, if the firm has 
many unrelated businesses, it would be beneficial for the shareholders to encourage the bad CEO to communicate with the uninformed board in this state. In state $(E 3, E 5)$, the magnitude of firm diversification affects the cutoff value $d_{(E 3, E 5)}^{*}$.

\section{Board Structure in Japan}

As discussed in the introduction, the board structure of Japanese firms has several distinct features. First, Japanese firms continue to prefer the Kansayaku system, even though it has a more limited ability to monitor management than the committees system, which has significantly strengthened the monitoring role of boards. Second, Japanese firms have been rapidly increasing the number of outside directors on their boards in recent years, even though most do not apply the committees system. Lastly, there remains significant variability in attitudes toward the hiring of outside directors across firms.

I can at least partially explain these features using my model. Regarding the first point, we can consider the committees system as an informed board with a majority of outsiders who have an enhanced monitoring power (i.e., small monitoring intensity cost), whereas the traditional Kansayaku system is relatively uninformed because it generally has many insiders with little incentive to monitor management (i.e., large monitoring intensity cost). Therefore, as in state $(E 3, E 4)$, shareholders may want to choose the Kansayaku system to encourage communication between management and the board members. The second point concerns the choice between the informed board with many outsiders and the uninformed board with few outsiders, both of which employ the Kansayaku system with its large monitoring intensity cost. Thus, Kansayaku firms are willing to hire additional outside directors because they can take advantage of outside information without worrying about miscommunication between management and the board. Nevertheless, some Japanese firms choose the committees system. The basic model implies that various firm-specific factors, including the CEO's and board's private benefit, management bias, and/or the importance of inside and outside information, also affect the firm's choice of board.

Regarding the third point, the extended models imply that firms choose the uninformed board that is friendlier to the CEO if the shareholders incur some costs when the board turns down the CEO's decision. In addition, a diversified firm may face some difficulty in finding a good CEO who can fully observe inside information. It can then be optimal for such a firm to choose the uninformed board with only a small number of outsiders, given it has many insiders who can collect sufficient inside information from each business unit. In the analysis below, I examine the relationship between foreign shareholders and board structure. Foreign shareholders have a smaller shareholders' cost if they are less reluctant than are Japanese shareholders to see the conflict between the board and management. In addition, I examine how the board structure differs across industries because firms involved in many businesses may have a smaller number of outside directors than those specializing in relatively few businesses.

Figure 5 depicts the relationship between the share of foreign shareholders and the 


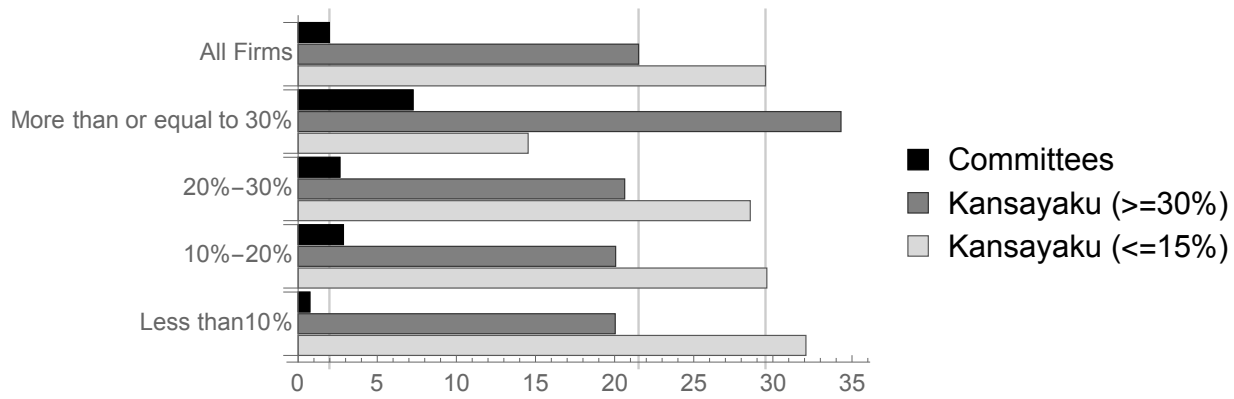

Figure 5. Foreign Shareholders and Board Structure The figure shows the relationship between the percentage of foreign shareholders and the board structures of TSE-listed firms. There are 3,491 sample firms, of which 344 have $30 \%$ or more foreign shareholders, 378 have from less than $30 \%$ to $20 \%, 628$ have from less than $20 \%$ to $10 \%$, and 2,141 have less than $10 \%$. For each of these subsamples, the black, gray, and light gray bars represent the percentage (\%) of firms with the committees system, Kansayaku firms with outside directors representing $30 \%$ or more of the board, and Kansayaku firms with outside directors representing $15 \%$ or less of the board, respectively. The grid lines indicate the percentages for all sample firms. The sample firms are from the corporate governance information search on May 7, 2016 and the list of TSE-listed issues on March 31, 2016, both of which are publicly available on the TSE website.

board structure. The sample is collected from the corporate governance information search on May 7, 2016 and the list of TSE-listed issues as of March 31, 2016 on the TSE's website. ${ }^{17}$ There are 3,491 firms in total, for which the average board size is 8.00 (7.97 for Kansayaku firms and 9.10 for committee firms) and the average number of outside directors is 1.77 (1.70 for Kansayaku firms and 5.05 for committee firms). I sort the sample into subsamples according to the share of foreign shareholders. For the 3,491 sample firms, 344 have $30 \%$ or more foreign shareholders, 378 have between less than $30 \%$ to $20 \%, 628$ have less than $20 \%$ to $10 \%$, and 2,141 have less than $10 \%$. For each subsample, the black, gray, and light gray bars represent the percentage of firms with the committees system, Kansayaku firms with outsiders representing $30 \%$ or more of the board, and Kansayaku firms with outsiders representing 15\% or less of board members, respectively. Across all of the sample firms, $29.53 \%$ are Kansayaku firms with at most $15 \%$ outsiders and $21.51 \%$ are Kansayaku firms with at least $30 \%$ outsiders. Committee firms account for a mere $1.98 \%$ of firms in the full sample.

As shown, among Kansayaku firms there is a clear positive correlation between foreign ownership and the number of outside directors. While $34.30 \%$ of the firms with $30 \%$ or more foreigner shareholders have at least $30 \%$ board outsiders, only $14.53 \%$ have at most $15 \%$ board outsiders. Conversely, $20.04 \%$ of firms with less than $10 \%$ foreign shareholders have at least $30 \%$ board outsiders, but $32.09 \%$ have at most $15 \%$ outsiders.

\footnotetext{
${ }^{17}$ In Figures 5 and 6 , the definition of Kansayaku firms includes both Kansayaku firms (3,093 firms) and firms with a Kansa committee (329 firms). The Kansa committee firms generally have many outside directors. Importantly, my interpretations remain valid even after excluding these firms from the sample.
} 
That is, the firms with many foreign shareholders who are likely to have small shareholders' costs associated with disagreement between the CEO and management tend to appoint many outside directors who can bring with them outside information, but also might harshly intervene in management's decisions. In contrast, Japanese shareholders with large shareholders' costs prefer to have inside directors. Similarly, firms with many foreign shareholders are less reluctant to adopt the committees system. In evidence, the shares of committee firms with $30 \%$ or more and $15 \%$ or less of foreign shareholders are $7.27 \%$ and $0.75 \%$, respectively.

Figure 6 illustrates board structure by industry sector. The sample is split into 17 industry sectors (firm observations for each sector in brackets): Foods (136), Energy Resources (20), Construction \& Materials (310), Raw Materials \& Chemicals (286), Pharmaceuticals (65), Automobiles \& Transportation Equipment (116), Steel \& Nonferrous Metals (80), Machinery (230), Electrical Appliances \& Precision Instruments (311), IT \& Services, Others (863), Electric Power \& Gas (23), Transportation \& Logistics (113), Commercial \& Wholesale Trade (319), Retail Trade (337), Banks (86), Financials (excluding Banks) (83), and Real Estate (113). For each subsample, the black, gray, and light gray parts represent the percentages of firms with the committees system, Kansayaku firms with outsiders representing $30 \%$ or more of the board, and Kansayaku firms with outsiders representing $15 \%$ or less of the board, respectively.

We find firms with the committees system across most of the industries except for Foods and Energy Resources. In particular, Pharmaceuticals (6.15\%), Banks (9.30\%), and Financials (excluding Banks) (12.05\%) have much higher percentage shares of committee firms than the full sample (1.98\%). Further, the Pharmaceutical and Financial industries have higher percentage shares of Kansayaku firms with at least $30 \%$ outsiders (33.85\% and $39.76 \%$, respectively) than the full sample $(21.53 \%)$ and lower percentage shares of Kansayaku firms with at most $15 \%$ outsiders $(16.92 \%$ and $8.42 \%$, respectively) than the full sample $(29.53 \%)$. Firms in these sectors are all engaged in highly specialized businesses, even though each pharmaceutical firm certainly develops many products. Accordingly, these firms may not need many insiders to collect inside information, but prefer to have outsiders to obtain useful outside information. Similarly, among Kansayaku firms, Energy Resources and Real Estate have high percentage shares of firms with at least $30 \%$ outside directors $(30.00 \%$ and $35.40 \%$, respectively), and low percentage shares of firms with at most $15 \%$ outsiders $(10.00 \%$ and $18.58 \%$, respectively). In general, the Real Estate and Energy Resources (e.g., oil companies) sectors are specialized, but not diversified. The IT \& Services, Others sector also has relatively many Kansayaku firms with at least $30 \%$ outsiders (29.42\%). Although IT firms are also involved in many projects, we usually find their businesses depend on core information technology. Furthermore, IT firms hire many board outsiders because they may need outside information to integrate their technology with other business fields.

In contrast, some industries have a large number of Kansayaku firms with few outsiders and a small number of Kansayaku firms with many outsiders. The percentage shares of Kansayaku firms with at most $15 \%$ outsiders for Construction \& Materials, Raw Materials \& Chemicals, Automobiles \& Transportation Equipment, Steel \& Nonferrous 
Metals, and Machinery are $41.49 \%, 34.27 \%, 36.24 \%, 33.75 \%$, and $25.65 \%$, while the percentage shares of Kansayaku firms with at least $30 \%$ outsiders for these same industries are $9.03 \%, 16.43 \%, 12.07 \%, 20.00 \%$, and $15.65 \%$, respectively. A common characteristic of these industries is that firms use high technology skills to produce goods and services and they are involved in many different projects. As those in each segmented business unit possess very technical knowledge, it may be difficult for the CEO to understand fully the firm's entire business, and the board can possibly play an important role in collecting inside information from each of these business units. For these industries, the relative importance of inside information is quite high, although outside information may also be important to expand their businesses into new areas. In addition, $33 \%$ of Commercial \& Wholesale Trade are Kansayaku firms with at most $15 \%$ outsiders, and only $14.42 \%$ are Kansayaku firms with at least $30 \%$ outsiders. As many of these general trading firms are involved in global businesses across a broad range of products and services, their boards need a sufficient number of insiders to collect inside information from each business unit.

However, inferences from casual observation of the data are not always consistent with the model's implications. For example, a relatively high percentage share of Kansayaku firms (33.63\%) in Transportation \& Logistics hire few board outsiders and only a relatively low percentage share of Kansayaku firms (15.93\%) in this sector appoint many outside directors. This is somewhat counterintuitive in that this industry is more or less specialized in transportation and generally has sufficient capacity to hire outsiders. In addition, Electrical Appliances \& Precision Instruments have similar characteristics to Machinery in the sense that the firms in both industries produce many different types of goods using high technology skills. However, in this industry, the percentage share of Kansayaku firms with at most $15 \%$ outsiders $(26.69 \%)$ is less than that of the full sample, and the percentage share of Kansayaku firms with at least 30\% outsiders is close to that of the full sample. This result possibly implies that Japanese large electronics firms, such as Sony and Hitachi, place more importance on acquiring outside information than on collecting inside information. 


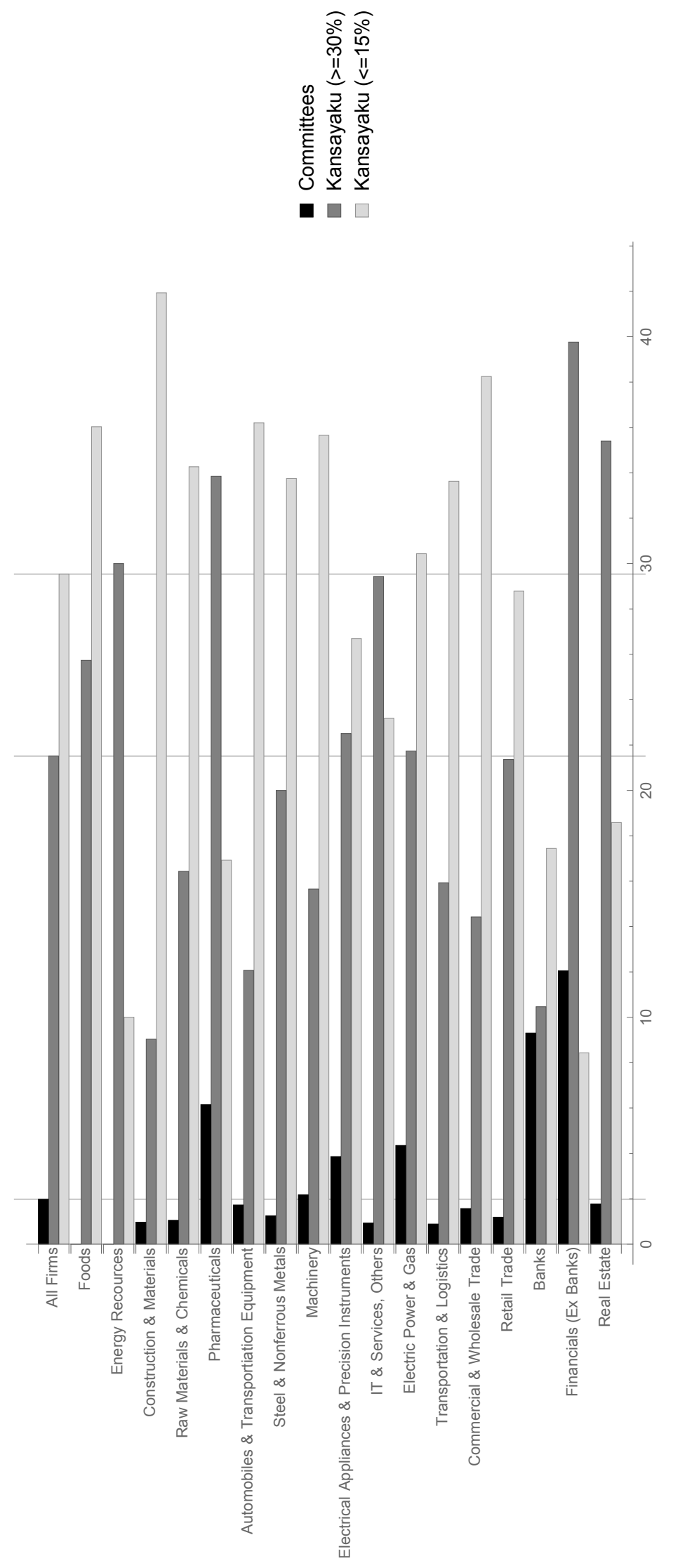

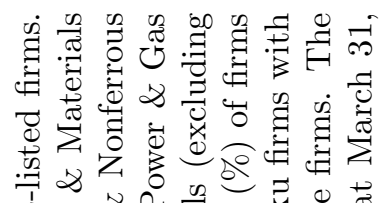

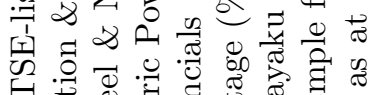

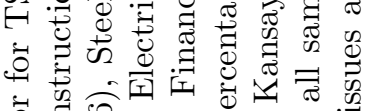

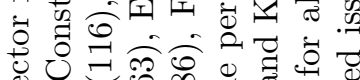

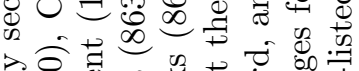

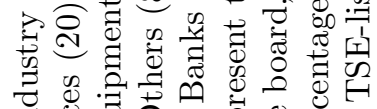

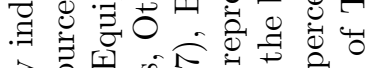

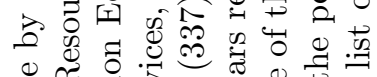

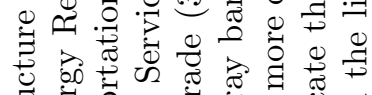

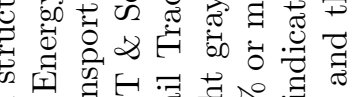

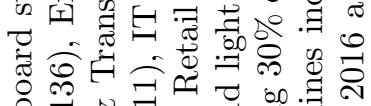

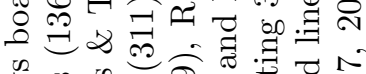

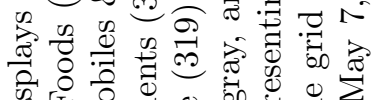

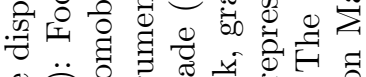

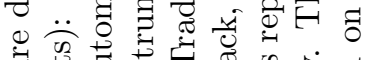

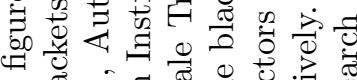

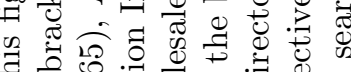

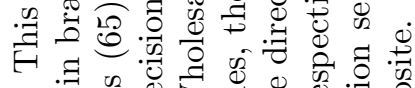
o.

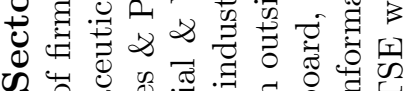

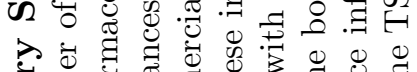

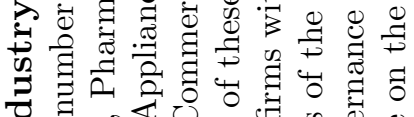

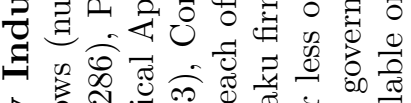

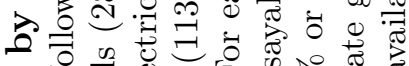

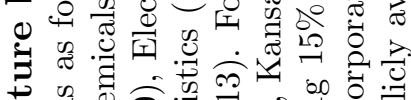

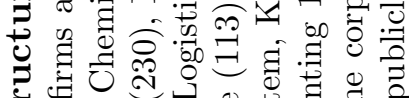

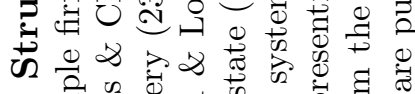
क

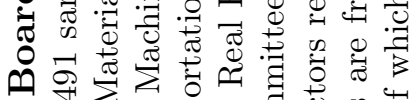

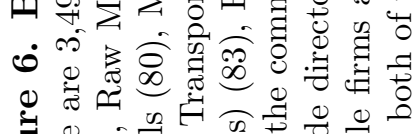

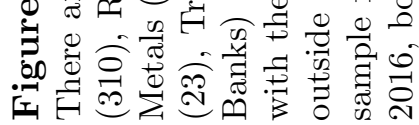




\section{Conclusion}

This paper considers several situations in which shareholders optimally choose the board that does not produce any outside information using the dual-role model of the board of directors in Adams and Ferreira (2007). My model confirms that it is generally optimal for shareholders to choose the informed board if the board has a large monitoring intensity cost. In this case, there is sufficient communication between the CEO and the board, and the informed board can remove the management bias associated with the CEO's decision, better advise the CEO, and if necessary, make a better project decision by bringing outside information into the firm.

However, in some situations, an uninformed board that merely considers inside information already available within the firm becomes optimal. First, when the informed board has a sufficiently small cost of monitoring intensity, both the good CEO who observes inside information and the bad CEO who does not observe it are unwilling to communicate with the informed board, as they are concerned about losing their decisionmaking power. However, the bad CEO still has an incentive to communicate with the "uninformed board," and the shareholders optimally choose the uninformed board to induce the bad CEO to reveal his project choice to the board. The uninformed board is then likely chosen, especially when the probability of selecting the bad CEO is high and the private information possessed by insiders is valuable. Second, board members may want to be "active" monitors if they can obtain some private benefit from taking control of the project decision. In particular, the informed board with a large private benefit may overturn the CEO's decision excessively and possibly make a worse decision than the CEO, and thus the optimal board can be uninformed because it has less incentive to oppose the CEO. ${ }^{18}$ Third, the shareholders' cost associated with the conflict between the board and the CEO can constrain shareholders in choosing the informed board. If the shareholders incur a large cost sufficient to offset the advantages of hiring the informed board, then the shareholders prefer the uninformed board, which has less incentive to reject the CEO's decision. Fourth, if a firm is involved in many businesses, especially if it is a "silo" company in which each business department does not share enough information with the others, each insider is likely to have a small piece of inside information about the firm's entire business. ${ }^{19}$ Then, the board may face a difficulty in finding a CEO with a sufficient amount of inside information. In such a situation, the board can play an important role in collecting inside information by appointing some insiders from each business unit to the board and helping the CEO use this information during the decision-making process. It can indeed then be optimal for a diversified firm to select the uninformed board with many insiders, as the board with many outsiders may fail to produce enough inside information, even if it can observe outside information. ${ }^{20}$ This

\footnotetext{
${ }^{18}$ Boards of Japanese firms may have a small private benefit because the market for independent directors does not function well in Japan.

${ }^{19}$ If employees of a company have a silo mentality, or an introversive mind-set that prohibits them from communicating with others, we would expect to see similar effects.

${ }^{20}$ The diversified firm can possibly obtain both inside and outside information by implementing a large board. However, it may take a longer time to gather the collective opinions of board members as board
} 
is especially so when the magnitude of firm diversification is large, the firm needs many outsiders to obtain useful outside information, and the inside information is valuable.

In recent years, Japanese firms have been increasing the number of outsiders on their boards, even while using the Kansayaku system instead of the committees system. We can at least partly understand this in that under the Kansayaku system, outside directors have a relatively large cost of monitoring intensity, and as a result, Japanese firms can easily hire additional outside board members to obtain outside information without worrying about miscommunication between the $\mathrm{CEO}$ and the board. In addition, the fact that firms with a greater number of foreign shareholders tend to have more outside board members can be explained by the implications of the model if foreign shareholders have greater tolerance for disagreement between the CEO and the board than do typical Japanese shareholders. Furthermore, consistent with some of the implications, highly specialized firms such as financial, real estate, and pharmaceutical firms tend to have a greater number of outside directors than do diversified firms such as chemical, machinery, and automobile firms that utilize technical skills to produce many different goods and services.

Although casual observations of data are important steps to linking the implications of the model to actual corporate governance, empirical procedures controlling for various other factors (e.g., the CEO's and the board's private benefit, management bias, and the importance of inside and outside information) are necessary to investigate the model's predictions more precisely. As for future research, as far as I am aware, an examination of the relationship between firm diversification and board structure based on the implications of my model would be new to the literature. Past studies (e.g., Coles, Danile, and Naveen (2008)) generally argue that more diversified firms have a greater need for advice and thus hire more independent directors. ${ }^{21}$ Beside the choice of board, there are also other empirical implications regarding the board's monitoring intensity and the CEO's decision to communicate with the board. In my model, the board monitors intensively when the monitoring cost is small, when the board's private benefit or the CEO's managerial bias is large, when it is informed about the CEO's project choice, when the CEO does not have inside information, and when the board itself can observe outside information. Regarding communication, the model predicts that managerial bias and the CEO's private benefit discourage the CEO from consulting with the board, while the board's private benefit encourages the $\mathrm{CEO}$ to communicate with the board. In addition, inside and outside information can exert different effects on the behavior of good and bad CEOs. When the outside information is valuable, both good and bad CEOs seek advice from outside board members. However, when the inside information is valuable, the bad CEO seeks advice from the board but the good CEO does not.

size becomes larger, and thus adopting a large board including both insiders and outsiders is not costless.

${ }^{21}$ Other studies including Boone, Field, Karpoff, and Raheja (2007), Dahya and McConnell (2007), Duchin et al. (2010), Ferreira et al. (2011), Guest (2008), Linck et al. (2008), and Masulis and Mobbs (2011) also use business segments as a proxy for the magnitude of firm diversification in their studies. Anderson, Bates, Bizjak, and Lemmon (2000), for instance, investigate 199 NYSE/AMEX firms from 1985 to 1994 and find that multiple-segment firms have larger boards and, contrary to our implications, more outside directors than do single-segment firms. 


\section{Appendix}

Proof of Proposition 2: The good CEO reveals $\theta$ to the informed board if:

$$
E U_{H G}\left(j=\theta ; I_{H}\right)-E U_{H G}\left(j=\emptyset ; I_{H}\right)=\left(\sigma_{a}^{2}-\sigma_{\epsilon}^{2}\right)+I_{H}\left(\sigma_{\epsilon}^{2}+\sigma_{p}^{2}\right)\left(\sigma_{\epsilon}^{2}-\sigma_{p}^{2}-b+d\right) \geq 0 .
$$

This condition holds for all $I_{H} \in(0,1]$ if $\sigma_{\epsilon}^{2}-\sigma_{p}^{2}-b+d \geq 0$. If $\sigma_{\epsilon}^{2}-\sigma_{p}^{2}-b+d<0$, this condition holds only if $I_{H} \leq \frac{\sigma_{a}^{2}-\sigma_{\epsilon}^{2}}{\left(\sigma_{\epsilon}^{2}+\sigma_{p}^{2}\right)\left(\sigma_{p}^{2}+b-\sigma_{\epsilon}^{2}-d\right)}$. Thus the good CEO reveals $\theta$ if $I_{H} \leq I^{*}$ and does not reveal it if $I^{*}<I_{H}$.

The bad CEO reveals $\theta$ to the informed board if:

$$
\begin{aligned}
E U_{H B}\left(j=\theta ; I_{H}\right)-E U_{H B}\left(j=\emptyset ; I_{H}\right) & =\left(\sigma_{a}^{2}-\sigma_{\epsilon}^{2}\right)+\left(\sigma_{p}^{2}-\sigma_{\eta}^{2}\right) \\
& +I_{H}\left(\sigma_{\epsilon}^{2}+\sigma_{\eta}^{2}\right)\left(\sigma_{\epsilon}^{2}+\sigma_{\eta}^{2}-b+d\right) \geq 0 .
\end{aligned}
$$

This condition holds for all $I_{H} \in(0,1]$ if $\sigma_{\epsilon}^{2}+\sigma_{\eta}^{2}-b+d \geq 0$. If $\sigma_{\epsilon}^{2}+\sigma_{\eta}^{2}-b+d<0$, this condition holds only if $I_{H} \leq \frac{\left(\sigma_{a}^{2}-\sigma_{\epsilon}^{2}\right)+\left(\sigma_{p}^{2}-\sigma_{\eta}^{2}\right)}{\left(\sigma_{\epsilon}^{2}+\sigma_{\eta}^{2}\right)\left(b-\sigma_{\epsilon}^{2}-\sigma_{\eta}^{2}-d\right)}$ and does not hold otherwise. Thus the bad CEO reveals $\theta$ if $I_{H} \leq I^{* *}$ and does not reveal it if $I^{* *}<I_{H}$.

Because $I^{*} \leq I^{* *}$, the good CEO never reveals $\theta$ when the bad CEO does not reveal it. Thus the equilibrium is state (E1) if $I_{H} \leq I^{*}$, state (E2) if $I^{*}<I_{H} \leq I^{* *}$, or state (E3) if $I^{* *}<I_{H}$.

Proof of Proposition 3: The good CEO does not reveal $\theta$ to the uninformed board because, with the condition $b \geq d$ :

$$
E U_{L G}\left(j=\theta ; I_{L}\right)-E U_{L G}\left(j=\emptyset ; I_{L}\right)=I_{L} \sigma_{p}^{2}\left(d-b-\sigma_{p}^{2}\right)<0,
$$

holds for all $I_{L} \in(0,1]$.

The bad CEO reveals $\theta$ to the uninformed board if:

$$
E U_{L B}\left(j=\theta ; I_{L}\right)-E U_{L B}\left(j=\emptyset ; I_{L}\right)=\left(\sigma_{p}^{2}-\sigma_{\eta}^{2}\right)+I_{L} \sigma_{\eta}^{2}\left(\sigma_{\eta}^{2}-b+d\right) \geq 0 .
$$

This condition holds for all $I_{L} \in(0,1]$ if $\sigma_{\eta}^{2}-b+d \geq 0$. If $\sigma_{\eta}^{2}-b+d<0$, this condition holds only if $I_{H} \leq \frac{\sigma_{p}^{2}-\sigma_{\eta}^{2}}{\sigma_{\eta}^{2}\left(b-\sigma_{\eta}^{2}-d\right)}$ and does not hold otherwise. Thus the bad CEO reveals $\theta$ if $I_{L} \leq I^{* * *}$, and the equilibrium state is (E4) if $I_{L} \leq I^{* * *}$ or (E5) if $I^{* * *}<I_{L}$.

Proof of Proposition 4: (a) In states $(E 1, E 4)$ and $(E 1, E 5)$, the following inequalities hold for all the parameter values.

$$
\begin{aligned}
E\left(U_{S}(E 1)\right)-E\left(U_{S}(E 4)\right) & =q\left[\left(\sigma_{a}^{2}-\sigma_{\epsilon}^{2}\right)+I_{H}\left(\sigma_{\epsilon}^{2}+2 g^{2}\right)^{2}+I_{H} d\left(\sigma_{\epsilon}^{2}+2 g^{2}\right)-I_{L}\left(2 g^{2}-\sigma_{p}^{2}\right)^{2}\right. \\
& \left.-I_{L} d\left(2 g^{2}-\sigma_{p}^{2}\right)\right]+(1-q)\left[\left(\sigma_{a}^{2}-\sigma_{\epsilon}^{2}\right)+I_{H}\left(\sigma_{\epsilon}^{2}+\sigma_{\eta}^{2}+2 g^{2}\right)^{2}\right. \\
& \left.+I_{H} d\left(\sigma_{\epsilon}^{2}+\sigma_{\eta}^{2}+2 g^{2}\right)-I_{L}\left(\sigma_{\eta}^{2}+2 g^{2}\right)^{2}-I_{L} d\left(\sigma_{\eta}^{2}+2 g^{2}\right)\right] \\
& \geq 0
\end{aligned}
$$




$$
\begin{aligned}
E\left(U_{S}(E 1)\right)-E\left(U_{S}(E 5)\right) & =q\left[\left(\sigma_{a}^{2}-\sigma_{\epsilon}^{2}\right)+I_{H}\left(\sigma_{\epsilon}^{2}+2 g^{2}+d\right)\left(\sigma_{\epsilon}^{2}+2 g^{2}\right)\right. \\
& \left.-I_{L}\left(2 g^{2}+d-\sigma_{p}^{2}\right)\left(2 g^{2}-\sigma_{p}^{2}\right)\right]+(1-q)\left[\left(\sigma_{a}^{2}-\sigma_{\epsilon}^{2}\right)+\left(\sigma_{p}^{2}-\sigma_{\eta}^{2}\right)\right. \\
& \left.+I_{H}\left(\sigma_{\epsilon}^{2}+\sigma_{\eta}^{2}+2 g^{2}+d\right)\left(\sigma_{\epsilon}^{2}+\sigma_{\eta}^{2}+2 g^{2}\right)-I_{L}\left(\sigma_{\eta}^{2}+d\right) 2 g^{2}\right] \\
& \geq 0 .
\end{aligned}
$$

Therefore, the shareholders always choose the informed board.

(b) In state $(E 2, E 4)$, the shareholders choose the informed board if:

$$
\begin{aligned}
E\left(U_{S}(E 2)\right)-E\left(U_{S}(E 4)\right) & =q\left[\left(I_{H}-I_{L}\right)\left(2 g^{2}-\sigma_{p}^{2}\right)\left(2 g^{2}-\sigma_{p}^{2}+d\right)\right] \\
& +(1-q)\left[\left(\sigma_{a}^{2}-\sigma_{\epsilon}^{2}\right)+I_{H}\left(\sigma_{\epsilon}^{2}+\sigma_{\eta}^{2}+2 g^{2}\right)^{2}+I_{H} d\left(\sigma_{\epsilon}^{2}+\sigma_{\eta}^{2}+2 g^{2}\right)\right. \\
& \left.-I_{L}\left(\sigma_{\eta}^{2}+2 g^{2}\right)^{2}-I_{L} d\left(\sigma_{\eta}^{2}+2 g^{2}\right)\right] \geq 0 .
\end{aligned}
$$

If $q\left(I_{H}-I_{L}\right)\left(2 g^{2}-\sigma_{p}^{2}\right)+(1-q)\left(I_{H}\left(\sigma_{\epsilon}^{2}+\sigma_{\eta}^{2}+2 g^{2}\right)-I_{L}\left(\sigma_{\eta}^{2}+2 g^{2}\right)\right) \geq 0$, the above condition is satisfied for all the parameter values. If not, the above condition is translated into:

$$
\begin{aligned}
d & \leq \frac{1}{-q\left(I_{H}-I_{L}\right)\left(2 g^{2}-\sigma_{p}^{2}\right)-(1-q)\left(I_{H}\left(\sigma_{\epsilon}^{2}+\sigma_{\eta}^{2}+2 g^{2}\right)-I_{L}\left(\sigma_{\eta}^{2}+2 g^{2}\right)\right)} \\
& \times q\left(I_{H}-I_{L}\right)\left(2 g^{2}-\sigma_{p}^{2}\right)^{2}+(1-q)\left[\left(\sigma_{a}^{2}-\sigma_{\epsilon}^{2}\right)\right. \\
& \left.+I_{H}\left(\sigma_{\epsilon}^{2}+\sigma_{\eta}^{2}+2 g^{2}\right)^{2}-I_{L}\left(\sigma_{\eta}^{2}+2 g^{2}\right)^{2}\right] .
\end{aligned}
$$

We let $d_{(E 2, E 4)}^{*}$ be equal to the right-hand side of this equation if its denominator takes a nonnegative value and $\infty$ otherwise. Then, the informed (uninformed) board is chosen if $d \leq d_{(E 2, E 4)}^{*}\left(d>d_{(E 2, E 4)}^{*}\right)$.

Similarly, in states $(E 2, E 5)$ and $(E 3, E 5)$, we define $d_{(\cdot, \cdot)}^{*}$ as:

$$
\begin{aligned}
d_{(E 2, E 5)}^{*} & =\frac{1}{-q\left(I_{H}-I_{L}\right)\left(2 g^{2}-\sigma_{p}^{2}\right)-(1-q)\left(I_{H}\left(\sigma_{\epsilon}^{2}+\sigma_{\eta}^{2}+2 g^{2}\right)-2 I_{L} g^{2}\right)} \\
& \times\left[q\left(I_{H}-I_{L}\right)\left(2 g^{2}-\sigma_{p}^{2}\right)^{2}+(1-q)\left\{\left(\sigma_{a}^{2}-\sigma_{\epsilon}^{2}\right)\right.\right. \\
& \left.\left.+I_{H}\left(\sigma_{\epsilon}^{2}+\sigma_{\eta}^{2}+2 g^{2}\right)^{2}-4 I_{L} g^{4}\right\}\right],
\end{aligned}
$$

if the denominator is nonnegative and $\infty$ otherwise, and

$$
d_{(E 3, E 5)}^{*}=\frac{q\left(I_{H}-I_{L}\right)\left(2 g^{2}-\sigma_{p}^{2}\right)^{2}+(1-q)\left(I_{H}-I_{L}\right) 4 g^{4}}{-q\left(I_{H}-I_{L}\right)\left(2 g^{2}-\sigma_{p}^{2}\right)-(1-q)\left(I_{H}-I_{L}\right) 2 g^{2}},
$$

if the denominator is nonnegative and $\infty$ otherwise. Then the informed (uninformed) board is chosen if $d \leq d_{((\cdot),(\cdot))}^{*}\left(d>d_{(\cdot \cdot),(\cdot))}^{*}\right)$. 
(c) In state $(E 3, E 4)$, the uninformed board is chosen if:

$$
\begin{aligned}
E\left(U_{S}(E 3)\right)-E\left(U_{S}(E 4)\right) & =q\left[\left(I_{H}-I_{L}\right)\left(2 g^{2}-\sigma_{p}^{2}\right)\left(2 g^{2}-\sigma_{p}^{2}+d\right)\right] \\
& +(1-q)\left[\left(\sigma_{\eta}^{2}-\sigma_{p}^{2}\right)+I_{H} 2 g^{2}\left(2 g^{2}+d\right)\right. \\
& \left.-I_{L}\left(\sigma_{\eta}^{2}+d+2 g^{2}\right)\left(\sigma_{\eta}^{2}+2 g^{2}\right)\right]<0
\end{aligned}
$$

and the informed board is chosen otherwise. If $I \equiv I_{H}=I_{L}$, the above condition is reduced to $E\left(U_{S}(E 3)\right)-E\left(U_{S}(E 4)\right)=(1-q)\left[\left(\sigma_{\eta}^{2}-\sigma_{p}^{2}\right)-I \sigma_{\eta}^{2}\left(\sigma_{\eta}^{2}+4 g^{2}+d\right)\right]<0$, which holds for all the parameter values.

Proof of Proposition 5: In state (E1,E4), the informed board is chosen if:

$$
\begin{aligned}
E\left(U_{S}(E 1)\right)-E\left(U_{S}(E 4)\right) & =F-c\left[q\left(I_{H}\left(\sigma_{\epsilon}^{2}+2 g^{2}+d\right)-I_{L}\left(2 g^{2}-\sigma_{p}^{2}+d\right)\right)\right. \\
& \left.+(1-q)\left(I_{H}\left(\sigma_{\epsilon}^{2}+\sigma_{\eta}^{2}+2 g^{2}+d\right)-I_{L}\left(\sigma_{\eta}^{2}+2 g^{2}+d\right)\right)\right] \\
& \geq 0 .
\end{aligned}
$$

where $F \geq 0$ is $E\left(U_{S}(E 1)\right)-E\left(U_{S}(E 4)\right)$ of the basic model (see the proof of Proposition 4). This condition is rearranged for $c$ as:

$$
\begin{aligned}
c & \leq F \times\left[q\left(I_{H}\left(\sigma_{\epsilon}^{2}+2 g^{2}+d\right)-I_{L}\left(2 g^{2}-\sigma_{p}^{2}+d\right)\right)\right. \\
& \left.+(1-q)\left(I_{H}\left(\sigma_{\epsilon}^{2}+\sigma_{\eta}^{2}+2 g^{2}+d\right)-I_{L}\left(\sigma_{\eta}^{2}+2 g^{2}+d\right)\right)\right]^{-1} .
\end{aligned}
$$

Thus, by letting the right-hand side be $c_{(E 1, E 4)}^{*}$, the informed (uninformed) board is chosen when $c \leq c_{(E 1, E 4)}^{*}\left(c>c_{(E 1, E 4)}^{*}\right)$.

Similarly, in state $(E 1, E 5)$, we set:

$$
\begin{aligned}
c_{((E 1),(E 5))}^{*} & =G \times\left[q\left(I_{H}\left(\sigma_{\epsilon}^{2}+2 g^{2}+d\right)-I_{L}\left(2 g^{2}+d-\sigma_{p}^{2}\right)\right)\right. \\
& \left.+(1-q)\left(I_{H}\left(\sigma_{\epsilon}^{2}+\sigma_{\eta}^{2}+2 g^{2}+d\right)-I_{L}\left(2 g^{2}+d\right)\right)\right]^{-1} .
\end{aligned}
$$

where $G \geq 0$ is $E\left(U_{S}(E 1)\right)-E\left(U_{S}(E 5)\right)$ of the basic model. Then, the informed (uninformed) board is chosen when $c \leq c_{((E 1),(E 5))}^{*}\left(c>c_{((E 1),(E 5))}^{*}\right.$ ).

Proof of Proposition 6: We use the following results:

$$
\begin{aligned}
E\left(\left(y_{a}^{H}-\tilde{a}\right)^{2}+\left(y_{p}^{H}-\tilde{p}\right)^{2} \mid j=\theta\right) & =E\left((a-\tilde{a})^{2}+\left(r\left(p_{1}-\tilde{p_{1}}\right)+(1-r)\left(E\left(\tilde{p_{2}}\right)-\tilde{p_{2}}\right)\right)^{2} \mid j=\theta\right) \\
& =(1-r)^{2} \sigma_{p}^{2} \\
E\left(\left(y_{a}^{G}-\tilde{a}\right)^{2}\right. & \left.+\left(y_{p}^{G}-\tilde{p}\right)^{2} \mid j=\theta\right)=\sigma_{\epsilon}^{2}+2 g^{2}
\end{aligned}
$$




$$
\begin{aligned}
E\left(\left(y_{a}^{B}-\tilde{a}\right)^{2}+\left(y_{p}^{B}-\tilde{p}\right)^{2} \mid j=\theta\right) & =\sigma_{\epsilon}^{2}+g^{2}+E\left[E \left(\left\{r\left(\frac{p_{i+1}+p_{i}}{2}-\tilde{p_{1}}-g\right)+\right.\right.\right. \\
& \left.\left.\left.+(1-r)\left(E\left(\tilde{p_{2}}\right)-\tilde{p_{2}}-g\right)\right\}^{2} \mid \tilde{p_{1}} \in\left[p_{i+1}, p_{i}\right]\right)\right] \\
& =\sigma_{\epsilon}^{2}+r^{2} \sigma_{\eta}^{2}+(1-r)^{2} \sigma_{p}^{2}+2 g^{2} .
\end{aligned}
$$

In states $(E 1, E 4)$ and $(E 2, E 4)$, the uninformed board is optimal if:

$$
\begin{aligned}
E\left(U_{S}(E 1)\right)-E\left(U_{S}(E 4)\right) & =q\left[\left(\sigma_{a}^{2}-\sigma_{\epsilon}^{2}\right)+I_{H}\left(\sigma_{\epsilon}^{2}+2 g^{2}+d-(1-r)^{2} \sigma_{p}^{2}\right)\left(2 g^{2}-\sigma_{\epsilon}^{2}-(1-r)^{2} \sigma_{p}^{2}\right)\right. \\
& \left.-I_{L}\left(2 g^{2}+d-\sigma_{p}^{2}\right)\left(2 g^{2}-\sigma_{p}^{2}\right)\right] \\
& +(1-q)\left[\left(\sigma_{a}^{2}-\sigma_{\epsilon}^{2}\right)+\left(1-r^{2}\right) \sigma_{\eta}^{2}-(1-r)^{2} \sigma_{p}^{2}\right. \\
& +I_{H}\left(\sigma_{\epsilon}^{2}+r^{2} \sigma_{\eta}^{2}+2 g^{2}+d\right)\left(\sigma_{\epsilon}^{2}+r^{2} \sigma_{\eta}^{2}+2 g^{2}\right) \\
& \left.-I_{L}\left(\sigma_{\eta}^{2}+2 g^{2}+d\right)\left(\sigma_{\eta}^{2}+2 g^{2}\right)\right]<0
\end{aligned}
$$

and

$$
\begin{aligned}
E\left(U_{S}(E 2)\right)-E\left(U_{S}(E 4)\right) & =q\left[I_{H}\left(2 g^{2}+d-\sigma_{p}^{2}\right)\left(2 g^{2}-\sigma_{p}^{2}\right)-I_{L}\left(2 g^{2}+d-\sigma_{p}^{2}\right)\left(2 g^{2}-\sigma_{p}^{2}\right)\right] \\
& +(1-q)\left[\left(\sigma_{a}^{2}-\sigma_{\epsilon}^{2}\right)+\left(1-r^{2}\right) \sigma_{\eta}^{2}-(1-r)^{2} \sigma_{p}^{2}\right. \\
& +I_{H}\left(\sigma_{\epsilon}^{2}+r^{2} \sigma_{\eta}^{2}+2 g^{2}+d\right)\left(\sigma_{\epsilon}^{2}+r^{2} \sigma_{\eta}^{2}+2 g^{2}\right) \\
& \left.-I_{L}\left(\sigma_{\eta}^{2}+2 g^{2}+d\right)\left(\sigma_{\eta}^{2}+2 g^{2}\right)\right]<0 .
\end{aligned}
$$

By letting $r=1$, we can verify that $E\left(U_{S}(E 1)\right)-E\left(U_{S}(E 4)\right)$ and $E\left(U_{S}(E 2)\right)-$ $E\left(U_{S}(E 4)\right)$ become the same equations as those in the basic model and thus the uninformed board is not chosen in state $(E 1, E 4)$ and also in state $(E 2, E 4)$ if $d \leq d_{(E 2, E 4)}^{*}$. By letting $N \uparrow \infty$ and $\alpha \downarrow 0$, for both $(E 1, E 4)$ and $(E 2, E 4)$, we can derive the same condition:

$$
\begin{aligned}
\left(\sigma_{a}^{2}-\sigma_{\epsilon}^{2}\right) & -\left(\sigma_{p}^{2}-\sigma_{\eta}^{2}\right)+I_{H} \sigma_{\epsilon}^{2}\left(\sigma_{\epsilon}^{2}+2 g^{2}\right) \\
& -I_{L} \sigma_{\eta}^{2}\left(\sigma_{\eta}^{2}+2 g^{2}\right)+\left(I_{H}-I_{L}\right)\left(2 g^{2}+d\right)\left(2 g^{2}+\sigma_{\epsilon}^{2}+\sigma_{\eta}^{2}\right)<0
\end{aligned}
$$

for selecting the uninformed board.

\section{References}

Adams, R. B., and D. Ferreira. 2007. A Theory of Friendly Boards. Journal of Finance 62:217-250. 
Adams, R. B., B. E. Hermalin, and M. S. Weisbach. 2010. The Role of Boards of Directors in Corporate Governance: A Conceptual Framework and Survey. Journal of Economic Literature 48:58-107.

Almazan, A., and J. Suarez. 2003. Entrenchment and Severance Pay in Optimal Governance Structures. Journal of Finance 58:519-548.

Anderson, R. C., T. W. Bates, J. M. Bizjak, and M. L. Lemmon. 2000. Corporate Governance and Firm Diversification. Financial Management 29:5-22.

Baldenius, T. 2013. Board Composition and CEO Power. Journal of Financial Economics 112:53-68.

Baranchuk, N., and P. H. Dybvig. 2006. Consensus in Diverse Corporate Boards. Review of Financial Studies 22:715-747.

Bebchuk, L. A., and M. S. Weisbach. 2010. The State of Corporate Governance Research. Review of Financial Studies 23:939-961.

Bhagat, S., and B. Bolton. 2013. Director Ownership, Governance, and Performance. Journal of Financial and Quantitative Analysis 48:105-135.

Boone, A. L., L. C. Field, J. M. Karpoff, and C. G. Raheja. 2007. The Determinants of Corporate Board Size and Composition: An Empirical Analysis. Journal of Financial Economics 85:66-101.

Brick, I. E., and N. Chidambaran. 2010. Board Meetings, Committee Structure, and Firm Value. Journal of Corporate Finance 16:533-553.

Byrd, J. W., and K. A. Hickman. 1992. Do Outside Directors Monitor Managers?: Evidence from Tender Offer Bids. Journal of Financial Economics 32:195-221.

Chhaochharia, V., and Y. Grinstein. 2007. Corporate Governance and Firm Value: The Impact of the 2002 Governance Rules. Journal of Finance 62:1789-1825.

Coles, J. L., N. D. Danile, and L. Naveen. 2008. Boards: Does One Size Fit All? Journal of Financial Economics 87:329-356.

Cornelli, F., Z. Kominek, and A. Ljungqvist. 2013. Monitoring Managers: Does It Matter? Journal of Finance 68:431-481.

Crawford, V. P., and J. Sobel. 1982. Strategic Information Transmission. Econometrica pp. 1431-1451.

Dahya, J., and J. J. McConnell. 2007. Board Composition, Corporate Performance, and the Cadbury Committee Recommendation. Journal of Financial and Quantitative Analysis 42:535-564. 
Dessein, W. 2002. Authority and Communication in Organizations. Review of Economic Studies 69:811-838.

Duchin, R., J. G. Matsusaka, and O. Ozbas. 2010. When Are Outside Directors Effective? Journal of Financial Economics 96:195-214.

Fahlenbrach, R., A. Low, and R. M. Stulz. 2010. Why Do Firms Appoint CEOs As Outside Directors? Journal of Financial Economics 97:12-32.

Faleye, O., R. Hoitash, and U. Hoitash. 2011. The Costs of Intense Board Monitoring. Journal of Financial Economics 101:160-181.

Ferreira, D., M. A. Ferreira, and C. C. Raposo. 2011. Board Structure and Price Informativeness. Journal of Financial Economics 99:523-545.

Fracassi, C., and G. Tate. 2012. External Networking and Internal Firm Governance. Journal of Finance 67:153-194.

Guest, P. M. 2008. The Determinants of Board Size and Composition: Evidence from the UK. Journal of Corporate Finance 14:51-72.

Harris, M., and A. Raviv. 2005. Allocation of Decision-Making Authority. Review of Finance 9:353-383.

Harris, M., and A. Raviv. 2008. A Theory of Board Control and Size. Review of Financial Studies 21:1797-1832.

Harris, M., and A. Raviv. 2010. Control of Corporate Decisions: Shareholders vs. Management. Review of Financial Studies 23:4115-4147.

Hermalin, B. E., and M. S. Weisbach. 1998. Endogenously Chosen Boards of Directors and Their Monitoring of the CEO. American Economic Review 88:96-118.

Hermalin, B. E., and M. S. Weisbach. 2003. Boards of Directors as an Endogenously Determined Institution: A Survey of the Economic Literature. Economic Policy Review $9: 7-26$.

Inderst, R., and H. M. Mueller. 2010. CEO Replacement under Private Information. Review of Financial Studies 23:2935-2969.

John, K., and L. W. Senbet. 1998. Corporate Governance and Board Effectiveness. Journal of Banking and Finance 22:371-403.

Knyazeva, A., D. Knyazeva, and R. W. Masulis. 2013. The Supply of Corporate Directors and Board Independence. Review of Financial Studies 26:1561-1605.

Kumar, P., and K. Sivaramakrishnan. 2008. Who Monitors the Monitor? The Effect of Board Independence on Executive Compensation and Firm Value. Review of Financial Studies 21:1371-1401. 
Linck, J. S., J. M. Netter, and T. Yang. 2008. The Determinants of Board Structure. Journal of Financial Economics 87:308-328.

Malenko, N. 2013. Communication and Decision-Making in Corporate Boards. Review of Financial Studies 27:1486-1532.

Masulis, R. W., and S. Mobbs. 2011. Are All Inside Directors the Same: Evidence from the External Directorship Market. Journal of Finance 66:823-872.

Nguyen, B. D., and K. M. Nielsen. 2010. The Value of Independent Directors: Evidence from Sudden Deaths. Journal of Financial Economics 98:550-567.

Perry, T., and A. Shivdasani. 2005. Do Boards Affect Performance? Evidence from Corporate Restructuring. Journal of Business 78:1403-1432.

Raheja, C. G. 2005. Determinants of Board Size and Composition: A Theory of Corporate Boards. Journal of Financial and Quantitative Analysis 40:283-306.

Ravina, E., and P. Sapienza. 2010. What Do Independent Directors Know? Evidence from Their Trading. Review of Financial Studies 23:962-1003.

Rosenstein, S., and J. G. Wyatt. 1990. Outside Directors, Board Independence, and Shareholder Wealth. Journal of Financial Economics 26:175-191.

Saito, T. 2011. Nihon Kigyou ni yoru Shagai Torishimariyaku no Donyuu no Kettei Youin to sono Kouka. In H. Miyajima (ed.), Nihon no Kigyou Touchi: Sono Saisekkei to Kyousouryoku no Kaifuku ni Mukete, chap. 4, pp. 181-213. Toyo Keizai Shinposha.

Schwartz-Ziv, M., and M. S. Weisbach. 2013. What Do Boards Really Do? Evidence from Minutes of Board Meetings. Journal of Financial Economics 108:349-366.

Shivdasani, A., and D. Yermack. 1999. CEO Involvement in the Selection of New Board Members: An Empirical Analysis. Journal of Finance 54:1829-1853.

Song, F., and A. V. Thakor. 2006. Information Control, Career Concerns, and Corporate Governance. Journal of Finance 61:1845-1896.

TSE. 2013. TSE Listed Companies White Paper on Corporate Governance 2013. Tokyo Stock Exchange, Inc.

Wagner, A. F. 2011. Board Independence and Competence. Journal of Financial Intermediation 20:71-93.

Warther, V. A. 1998. Board Effectiveness and Board Dissent: A Model of the Board's Relationship to Management and Shareholders. Journal of Corporate Finance 4:53-70. 